\title{
EVIDENCIAS FORMATIVAS EN UNA VÍA interregional entre San Pedro de Atacama y el Altiplano de Lípez ${ }^{1}$
}

\author{
Gonzalo Pimentel G. ${ }^{2}$
}

\section{* INTRODUCCIÓN}

Resumen

Se presentan los resultados de la prospección pedestre de una ruta que comunicó el Altiplano de Lípez (Departamento de Potosí, Bolivia) con los nodos formativos de Ghatchi y Calar en la cuenca del Vilama (San Pedro de Atacama, Chile), analizándose las evidencias sobre la movilidad interregional: red vial, sitios de descanso, sitios

ceremoniales, estructuras de señalización y bienes muebles. A partir de estos datos se discute el reconocimiento de una incipiente movilidad caravanera, junto a las características de la infraestructura, prácticas y estrategias desplegadas por los contingentes móviles formativos. Se plantea que fue una ruta tempranamente usada en el Formativo, siendo uno de los ejes viales más antiguos reconocidos para la circumpuna.

Palabras claves: San Pedro de Atacama - Altiplano de Lípez - análisis de redes viales - movilidad caravanera - Período Formativo.

Abstract

A survey by foot of the prehispanic route connecting the Highlands of Lípez (Department of Potosí, Bolivia) to the Formative Period sites of Ghatchi and Calar (Vilama river basin, San Pedro de Atacama, Chile), allowed us to analyze roadworks, rest sites, ceremonial places, signalling structures and transportable artifacts that stand out as evidence of interregional mobility. We discuss and propose indicators for the recognition of the early stages of caravanning, and trace the possible origins of the main users of this route during the Formative Period. Results demonstrate this to be the oldest route so far described in Chile.

Key words: San Pedro de Atacama - Altiplano of Lípez - roadwork analysis - caravan mobility - Formative Period.

Recibido: febrero 2006. Aceptado: octubre 2007.
El proceso de complejización social que caracterizó al Período Formativo en San Pedro de Atacama fue posible gracias a la integración dentro de una extensa red de interacción e intercambio socioeconómico a escala suprarregional, tal como lo atestigua la presencia de materiales procedentes del Noroeste Argentino, altiplano boliviano y costa del Pacífico en distintos contextos de la zona y sus alrededores (p.e., Núñez 1992a, 1994; Núñez y Dillehay 1995 [1979]; Llagostera 1996; Agüero 2005; Núñez et al.2007). Obviamente, esto implicó que determinados grupos necesariamente tuvieran que realizar largas jornadas de viaje desde sus centros de origen con el objeto de activar y mantener dichas relaciones sociales. Estos circuitos de movilidad, recurrentes en el tiempo, fueron produciendo diversas estrategias pautadas en el ritmo de viaje, en la elección del transecto vial, la disposición de los lugares de descanso y sitios ceremoniales, así como en la particularidad de los materiales que acompañaron a los viajeros. Las amplias distancias que incorporó la red vial circumpuneña y sus conexiones históricas con el Altiplano Central nos señalan que desde tiempos tempranos (ca. $1300 \mathrm{AC}$ ), estos sistemas de comunicación ya debieron estar completamente en funcionamiento.

Con este trabajo esperamos contribuir al reconocimiento de las relaciones interregionales con San Pedro de Atacama, a partir de las evidencias dejadas por los contingentes

\footnotetext{
${ }^{1}$ Proyectos FONDECYT 1030931 y 1011006. Parte de este trabajo se inserta en mi Tesis de Magíster en Antropología: "Arqueología vial. El caso de una ruta de interacción entre el Altiplano Meridional y San Pedro de Atacama", Universidad Católica del Norte, Universidad de Tarapacá, San Pedro de Atacama.

2 Universidad Católica del Norte. Gustavo Le Paige 380, San Pedro de Atacama, CHILE. Email: gpimentel@ucn.cl
} 
móviles que se desplazaron por estos amplios espacios. Así, se da a conocer el caso de estudio de un sistema vial interregional que conectó desde la vertiente oriental de la cordillera por el noreste con San Pedro de Atacama, y en el cual se establecieron conexiones específicas y directas con los nodos prehispánicos de Ghatchi y Calar en la cuenca del Vilama. Para ello, comenzamos desglosando las potencialidades del análisis vial y los objetivos específicos de nuestra investigación. Seguidamente, fundamentamos la elección del caso de estudio y exponemos los antecedentes arqueológicos, etnográficos e históricos, así como la metodología utilizada para el reconocimiento, registro y análisis de la vía estudiada. Luego, se presentan los hallazgos arqueológicos identificados en asociación al eje vial, analizándose la relación entre los condicionantes espaciales y la disposición del trazado, las características formales de la vía, sitios, estructuras y bienes muebles de tiempos formativos. Finalmente, se discuten la infraestructura, prácticas rituales y organización implicada en la movilidad internodal formativa.

\section{* Potencialidades del anÁlisis VIal}

Teniendo en cuenta que para el Norte Grande de Chile las redes viales prehispánicas son una evidencia tangible y directa de las conexiones e interacciones entre regiones distantes, su estudio nos permite obtener datos claves para reconocer aspectos de la organización social destinados a la movilidad, así como parte del sistema de interacción socioeconómica. Siguiendo a Trombold (1991), esto comprende dos tipos de análisis: uno micromorfológico orientado a aquellos aspectos formales, cronológicos y funcionales de las vías, y otro macromorfológico destinado a la interpretación de la organización involucrada en el ejercicio de la movilidad y de la interacción intersocietal. Esto lo abordamos a partir de seis objetivos que se explicitan a continuación.

Relación entre el espacio físico y eje vial. Asumiendo que las condiciones topográficas y ambientales son determinantes fundamentales en la disposición del transecto vial especialmente en una región que se caracteriza por una accidentada geomorfología y con recursos extremadamente circunscritos, ello debió implicar la toma de decisiones racionales, de costo y beneficio, en relación al movimiento por un medio físico determinado. De acuerdo a lo anterior, nos propusimos analizar la estrecha relación entre el trazado vial y las características topográficas y ambientales, lo que incluyó observar las distancias entre puntos con importantes recursos para el viajero (agua, forraje u otras fuentes de aprovisionamiento) y detectar de qué modo ello pudo incidir o no en el emplazamiento de los sitios de descanso y en la regulación del ritmo de tránsito.

Características formales de la vía. Respecto de éstas, se pueden distinguir dos tipos generales que dan cuenta del nivel de la escala social y grado de institucionalización de las redes viales para una determinada sociedad: 1) En un extremo los senderos como aquellos rasgos que no poseen ningún tipo de intervención constructiva, producidos por el simple tránsito redundante sobre un espacio definido, lo cual sería propio de las sociedades pre-estatales; 2) En el otro extremo los caminos como aquellas vías que incorporaron elementos tecnológicos estandarizados, así como especialistas dedicados a su construcción y mantención, siendo característicos de sociedades estatales (Earle 1991). Existe consenso de que en la circumpuna los caminos formalizados surgieron recién con el Estado incaico, y que previo a éste existieron senderos que quedaron muy bien marcados sobre la superficie gracias a las excelentes condiciones de conservación del desierto (Nielsen 2003; Berenguer 2004; Castro et al.2004; Pimentel 2004). Esto motivó la búsqueda de definiciones más precisas para identificar los senderos troperos de llamas. Núñez $(1976,1984)$ señala que lo característico del tránsito con recuas de llamas son los senderos paralelos de patrón "rastrillado", y recientemente, Berenguer (2004: 276) ha intentado distinguir entre senderos de llamas de otros animales de carga de tiempos históricos como los mulares, a partir de la etología de movilidad de las primeras. Indica que las mulas se desplazan en filas, al contrario de las recuas de llamas que se desplazan en grupos compactos dejando múltiples surcos angostos, sinuosos y "anastomosados", esto es, sendas interconectadas o superpuestas. El análisis de las características morfológicas de los senderos será clave para evaluar la presencia de una movilidad caravanera en tiempos formativos. 
Características formales y espaciamiento de los sitios de tránsito. Un tipo de sitio que concentra buena parte de la organización, infraestructura y escala social de la movilidad son los paraderos o campamentos de pernocte de los viajeros. Conocidos en el Altiplano de Lípez como jaras (Nielsen 1997), y en el lado chileno como paskanas (Núñez 1984), han sido descritos etnoarqueológicamente como pequeñas estructuras que presentan mínima inversión arquitectónica, donde se llevaron a cabo actividades básicas de preparación y consumo de alimentos y reparación de equipos, entre otros (Lecoq 1987; Nielsen 1997). Un tema a evaluar es si los campamentos de tránsito de tiempos formativos muestran características formales diferenciales en cuanto al emplazamiento, patrones arquitectónicos u otros rasgos que nos puedan orientar en la logística de la movilidad formativa. Por otra parte, al ser las paskanas las evidencias más directas del final de una jornada de viaje, el análisis de su espaciamiento permitirá conocer las distancias entre jornadas.

Emplazamiento y características formales de los sitios ceremoniales y estructuras de señalización. Los largos viajes también incluyeron actividades de carácter ceremonial que se llevaron a cabo en espacios de tránsito con una alta significación simbólica. Principalmente asignado a los períodos tardíos, el rito de la apacheta, los "sepulcros", "muros y cajas" y las representaciones rupestres son parte de esta diversidad ritual desplegada por los contingentes en tránsito (p.e., Núñez 1976, 1985; Yacobaccio 1979; Nielsen 1997, 2006; Berenguer 2004). Para el Período Formativo, hasta ahora no se cuenta con antecedentes claros de sitios ceremoniales en asociación a las rutas interregionales, lo que lleva a preguntarse si ello se debe a una real ausencia de ritualidad en el viaje, o bien, responde a que no se ha reconocido en el registro arqueológico. Del mismo modo, son parte del paisaje vial pequeños amontonamientos de piedras que sirvieron para señalizar el trayecto, y sobre los que sólo en el último tiempo se ha empezado a discutir su posible origen temporal (Berenguer et al.2005). De esta manera, a partir de las características formales, emplazamiento, intervisibilidad y distancia con el eje vial, se analizan aquellos sitios ceremoniales y estructuras de señalización que se asocian a algún tipo de evidencia de épocas formativas, explorándosey discutiéndose si ya eran parte de la ritualidad e infraestructura vial de aquellos tiempos.
Características de los materiales muebles. Estos materiales asociados a los sitios y a la vía de circulación permiten aproximarnos a los bienes con que el viajero transitaba, y en el caso de indicadores como la cerámica, asignarle una datación relativa al uso de la vía. Este material también será útil para investigar el potencial origen de los contingentes móviles, a partir del análisis de la presencia/ausencia, recurrencia y distribución de ciertos tipos alfareros característicos de determinados grupos sociales. Por cierto, este análisis no está exento de problemas dado que la procedencia de los bienes y el origen de los grupos móviles no son necesariamente equivalentes, como advierte Nielsen (1997), al indicar que los grupos caravaneros actuales no sólo utilizan en el viaje artefactos procedentes de otras localidades sino incluso intercambian recursos de múltiples orígenes.

Conexión directa con los nodos prehispánicos. Tal como lo señalaba Hyslop (1991), la conexión última de la vía con los asentamientos principales es un dato relevante que confirma el uso de la vía en los momentos en que dichos asentamientos fueron ocupados. Son segmentos viales que informan con mayor confiabilidad sobre las características de la ruta en el período que conectó con el asentamiento, siempre y cuando no tenga importantes transformaciones posteriores. En tal sentido, el análisis en terreno se orientó a identificar las conexiones directas que tuvo la ruta con los nodos formativos de Ghatchi y Calar en la cuenca del Vilama, en el entendido de que estas conexiones últimas debiesen ser indicadores de una mayor intensidad de uso para dichos momentos.

\section{* Fundamentación, ANTeCedentes del CASo de ESTUDIO Y METODOLOGÍA}

Un primer análisis de las imágenes satelitales y de la cartografía de la porción noreste de San Pedro de Atacama $\left(22^{\circ}\right.$ Lat. Sur a $22^{\circ} 53^{\prime}$ Lat. Sur) permitió reconocer seis portezuelos o pasos que conectaron las vertientes oriental y occidental de la cordillera andina. ${ }^{3}$

\footnotetext{
3 De norte a sur son: 1) Paso Silala ( $22^{\circ}$ Lat. Sur) que vinculó con el río San Pedro-Loa (Santa Bárbara) y con conexiones a Turi siguiendo el paso entre los cerros Paniri y Echao; 2 ) Portezuelo de Linzor o Tierra Amarilla en el lado boliviano $\left(22^{\circ} 10^{\prime}\right.$ Lat. Sur $)$ con vinculación directa a la localidad de Toconce; 3 ) Portezuelo del Panizo ( $22^{\circ} 23^{\prime}$ Lat. Sur) con conexiones a Caspana y a San Pedro de Atacama; 4) Paso de Tocorpuri
} 
De éstos, el Portezuelo de Tocorpuri mostró interesantes antecedentes ya que tiene múltiples conexiones en su entrada a la región atacameña, comunicando al oeste directamente con las tierras altas de Caspana y al sur con San Pedro de Atacama, vía Machuca y Felon. Además, coincide con el eje más recto para comunicar Tiwanaku y San Pedro de Atacama pudiendo ser, probablemente, la vía de circulación utilizada en el Período Medio para conectar ambas esferas de interacción (Núñez et al.1997; Nielsen 2006).

Philippi (1860: 64) lo describe como el "camino de las pintadas" debido a la existencia de un lugar con gran cantidad de petroglifos. Posteriormente, este sitio de arte rupestre es denominado Catarpe por Le Paige (1964) y renombrado como Cuchabrache por Núñez y colaboradores (1997), quienes señalan su asociación a una ruta caravanera prehispánica con conexiones al altiplano ("la ruta de la coca"). Otros antecedentes arqueológicos sobre la vía son dados por Le Paige (1964), quien menciona una apacheta ubicada a media distancia entre Machuca y Pelun (o Pelon; los lugareños actualmente lo nombran como Felon), de donde recolectó 2072 piezas líticas y una gran pala de algarrobo. Asimismo, a $4 \mathrm{~km}$ de la apacheta y sobre el sendero hacia Machuca, registró material lítico similar al del sitio anterior, recolectando 33 piezas.

Sin embargo, pese al conocimiento de la existencia de esta vía no se realizaron estudios sistemáticos de su trayecto. Sólo recientemente Nielsen (2006) hizo el registro de $20 \mathrm{~km}$ lineales en el lado boliviano (Corredor Laguna Colorada, sector Huayllajara), brindando por primera vez información sobre el tráfico en este sector. Identificó varios segmentos de senderos, localizando 41 sitios de descanso nocturno, 25 de ellos con evidencias de alfarería prehispánica, y cuatro "sepulcros". A partir de la presencia de cerámica Los Morros-A, concluye que fue una vía utilizada por lo menos desde el Formativo Temprano, lo que corrobora con una fecha radiocarbónica de $2750 \pm 60$ AP.

( $22^{\circ} 29^{\prime}$ Lat. Sur) también con vinculaciones a Caspana y a San Pedro de Atacama; 5) Portezuelo de Chaxas ( $22^{\circ} 48^{\prime}$ Lat. Sur) con comunicaciones a San Bartolo y San Pedro de Atacama; y 6 ) Portezuelo del Cajón $\left(22^{\circ}\right.$ 53 ' Lat. Sur) con conexión directa a San Pedro de Atacama.
Contando con algunas referencias sobre la vía (expediciones, cartografía, arqueología), nos abocamos a su reconocimiento en terreno, registrando segmentos en los sectores de Cuchabrache, Machuca y Vega de Putana. Ello permitió organizar una prospección sistemática pedestre y de cobertura total de la ruta $(60 \mathrm{~km})$ desde el Portezuelo de Tocorpuri (frontera chilena-boliviana) hasta Catarpe en San Pedro de Atacama (Pimentel et al. 2007), con la cual determinamos que la vía se usó por lo menos desde el Período Formativo con continuidad en el Período Medio, Intermedio Tardío, Tardío y en momentos históricos tempranos y recientes (Figura 1). ${ }^{4}$ Además, se identificó un ramal en el Llano de Felon que se dirige al sector de Ghatchi en la cuenca del Vilama, otro ramal que continúa a Calar también en dicha cuenca, un ramal que continúa vía quebrada del Diablo a los oasis de San Pedro, y otro que conectó con Catarpe.

Recientes estudios desarrollados en los asentamientos de Ghatchi y Calar (Agüero 2005; Agüero y Uribe 2008) han empezado a aclarar sus distintos momentos de ocupación durante el Período Formativo, así como el carácter y naturaleza de éstos, lo cual permite contar con referencias más precisas para el análisis de la estrecha relación entre las redes viales y estos asentamientos.

Los sitios de Ghatchi comprenden al menos cinco asentamientos que se localizan en dos sectores diferenciados de la meseta oeste de la cuenca del Vilama. En las cercanías a Lomas Negras se emplazan los sitios Ghatchi-1Ay Ghatchi-1B, mientras que a unos $600 \mathrm{~m}$ al sur, separados por un pequeño lomaje, se localizan los asentamientos Ghatchi-2 $\mathrm{A}^{5}$, Ghatchi-2 B y Ghatchi-2C. Ghatchi-1A es un conjunto de al menos 21 estructuras aglutinadas construidas con muros de piedra dobles con relleno, y fue ocupado durante el Formativo Temprano y Formativo Medio-Tardío, y reutilizado durante el Período Medio e Intermedio Tardío, continuando, al parecer, hasta momentos actuales. Por su parte, Ghatchi-1B corresponde a un conjunto de 12 estructuras circulares

\footnotetext{
4 Prospección financiada por el Proyecto FONDECYT 1011006.

5 Con la excepción de este sitio asignado al Período Arcaico, todos los demás asentamientos poseen ocupaciones del Período Formativo, por lo cual se hace referencia solamente a estos últimos.
} 


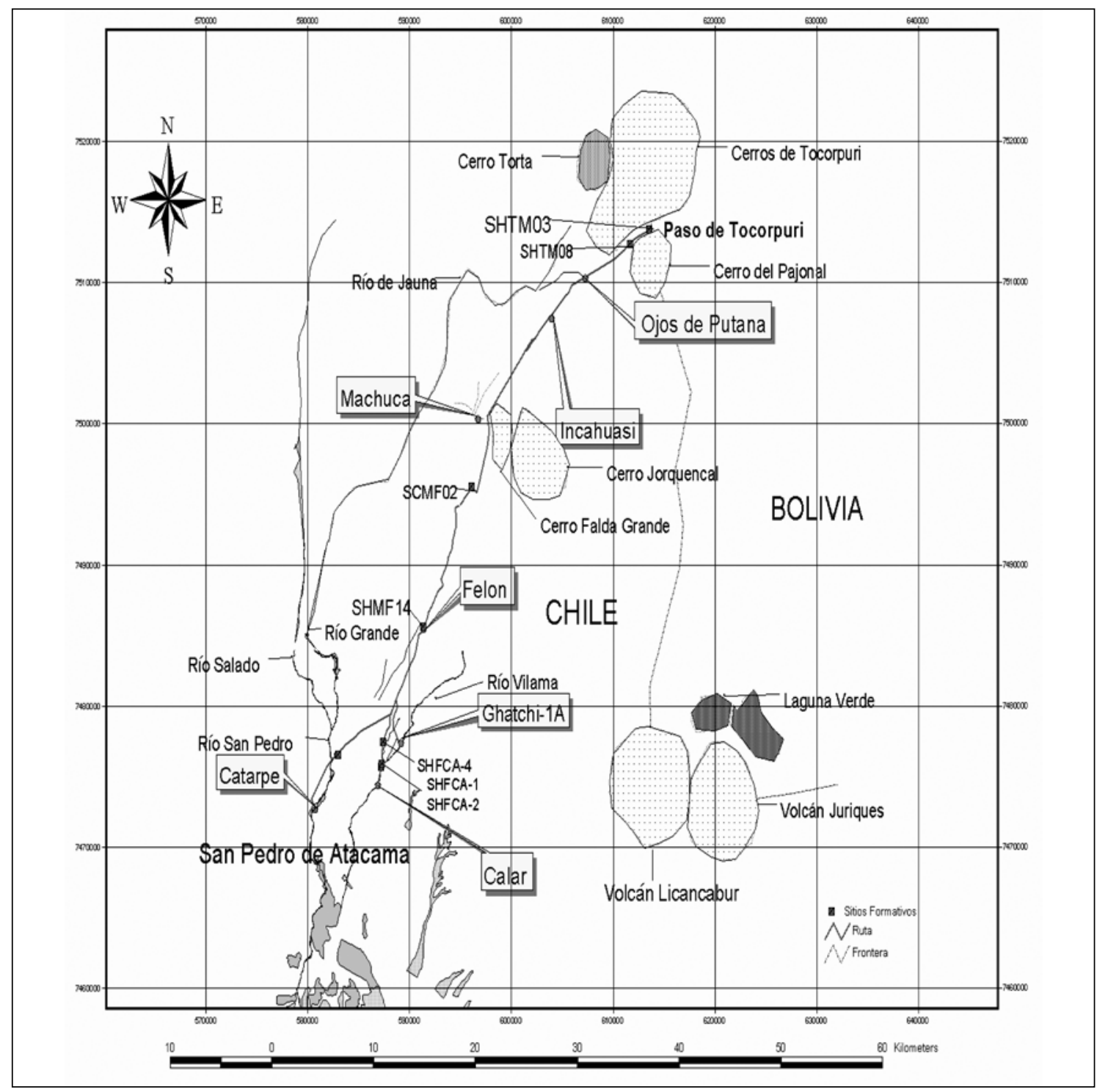

Figura 1. Mapa con el trazado de la vía formativa entre Tocorpuri y los nodos de Ghatchi y Calar.

aglutinadas de muros dobles con relleno, el cual cuenta con un fechado del piso ocupacional de $1650 \pm 95$ AP (210-620 cal. DC), que lo asigna al Formativo Tardío (Agüero y Uribe 2008).

En la meseta de Ghatchi-2, se ubica el sitio Ghatchi-2B, el cual corresponde a un conjunto de 30 estructuras de muros simples y dobles con relleno, algunas con el patrón de recinto central con otros menores adosados (Adán y Urbina 2007). Posee dos momentos ocupacionales, uno transicional Arcaico-Formativo y otro Formativo Temprano. En tanto, el sitio Ghatchi-2C se compone de 81 estructuras dispersas de formas circulares, ovales y subcirculares, con paramentos de hilada simple y en menor proporción muros dobles y dobles con relleno. Posee al menos tres momentos ocupacionales: una primera ocupación arcaica tardía con un fechado de $4885 \pm 125 \mathrm{AP}$ (4000-3350 cal. $\mathrm{AC})$, a la que sigue otra probablemente del Formativo Temprano y una final del Formativo Medio-Tardío (Agüero y Uribe 2008).

Por su parte, la aldea de Calar fue reconocida por Le Paige (1963-1965) y luego estudiada por Llagostera 
(1988) y Orellana (1988-89, 1990). Los recientes trabajos en Calar indican que está conformada por 43 recintos distribuidos en una superficie de $2950 \mathrm{~m}^{2}$. Predominan los recintos circulares, subcirculares y en menor medida los de planta irregular y rectangular. De acuerdo a los nuevos estudios, Calar habría tenido una larga ocupación desde el Arcaico Tardío, Formativo Temprano, Formativo Medio-Tardío con continuidad hasta momentos históricos. Sin embargo, su ocupación más intensa ocurriría durante el Formativo (Agüero 2005; Adán y Urbina 2007; Agüero y Uribe 2008).

Con estos antecedentes iniciamos la prospección de los ramales que se desprenden del Llano Felon a los asentamientos de Ghatchi y Calar. ${ }^{6}$ Para identificar las conexiones viales con estos sitios, primero se realizaron prospecciones radiales en ellos, con el objeto de identificar las vías que se desprenderían hacia el noroeste y que debían tener conexión con la ruta de Tocorpuri en el Llano Felon. Luego se realizó una prospección pedestre con cobertura total de ambos ramales.

Para la descripción vial se dividió la vía en tres tramos altitudinales: 1) Tocorpuri-Machuca (4600-4100 m.snm); 2) Machuca-Felon (4100-3200 m.snm); 3) Llano Felon-Ramal Ghatchi ( $2880-2767 \mathrm{~m} . \mathrm{snm})$; y 3.1) Llano Felon-Ramal Calar (2800-2650 m.snm). En cada uno de ellos se relevó el conjunto de evidencias antrópicas y las características topográficas y ambientales. Cada hallazgo arqueológico fue posicionado con GPS (Datum PSAD 56), llenando fichas en cada punto en que la ruta mostró algún cambio relevante (formal o espacial), o bien cuando se observaron sitios o materiales asociados. En los casos en que no se dio ninguna de esas situaciones se completaron fichas cada una distancia máxima de $800 \mathrm{~m}$. La ficha de registro vial incluyó datos sobre la orientación, ancho total, evidencias de arreglos, la forma del perfil longitudinal (plano, inclinado, escalonado, etc.), comportamiento en planta (recto, sinuoso, etc.) y corte transversal (recto, cóncavo, surcado, etc.) (Castro et al. 2004). Además, se consideró el número de sendas, distancia máxima entre

\footnotetext{
${ }^{6}$ La prospección de los ramales a Ghatchi y Calar fue realizada dentro del Proyecto FONDECYT 1030931.
}

ellas, la superposición de sendas y todos los ramales que se desprenden de la vía.

En el caso del registro arquitectónico se consideró el relevamiento del número de recintos, dimensiones, forma de la planta, tipo de hilada, tipo de aparejo, tipo de material, presencia de vanos, fundaciones u otros rasgos (Castro $e t$ al.1993), con fotografías y croquis a escala de cada recinto. También se recolectó material cerámico diagnóstico según criterios de forma, tratamiento de superficie y pasta. Se tomaron muestras del material lítico de acuerdo al tipo de materia prima, tipo de artefacto y etapas presentes de la cadena productiva. Finalmente, toda la información fue traspasada y sistematizada en un Sistema de Información Geográfica (SIG), usando para ello el programa ArcView 3.2, lo que permitió realizar análisis más precisos sobre la relación entre la vía y el espacio físico, distancias de fuentes de aprovisionamiento, espaciamiento entre los sitios, así como generar una cartografía detallada de la red vial y los sitios.

\section{- Características del espacio transitado}

La vía prospectada entre Tocorpuri y Calar desciende desde los 4600 hasta los $2650 \mathrm{~m} . \mathrm{snm}$ por un plano inclinado con un desnivel de $1950 \mathrm{~m}$. Siguiendo la gradiente altitudinal, la ruta atraviesa tres zonas climáticas de acuerdo a la clasificación de Koeppen (IGM 1990), el Clima de Estepa Fría de Altura (BSH), el Desierto Marginal de Altura (BWH) y el Desértico Normal (BW). Tomando como referencia la clasificación de pisos vegetacionales realizada en el Salar de Atacama por Villagrán y colaboradores (1998), se identificaron en todo el recorrido cuatro pisos vegetacionales: 1) sobre los $4350 \mathrm{~m} . \mathrm{snm}$ el piso Andino Subnival con una cobertura muy rala de pequeñas hierbas en rosetas y cojines; 2) el piso Altoandino o Pajonal entre 4350 y los $3900 \mathrm{~m} . \mathrm{snm}$, con fisionomía esteparia, dominado por gramíneas en champas y plantas en cojines; 3 ) el piso Puneño o Tolar entre los 4000-3800 a 3400 m.snm, que corresponde a un semidesierto, con arbustos 0 tolas, y 4) el piso Prepuneño entre los 3400 y 2600 $\mathrm{m} . \mathrm{snm}$ con una cobertura muy rala, siendo el de menor 
diversidad vegetacional donde predomina el arbusto Acantholippia punensis (rica-rica).

La parte alta del eje vial, entre Tocorpuri y Machuca, cubre una distancia de $23 \mathrm{~km}$, descendiendo desde los 4600 hasta los 4100 m.snm. Corresponde a un plano inclinado con lomajes suaves, quebradas menores que se activan intermitentemente y tres hoyadas azonales de vegas permanentes: Putana, Incahuasi y Machuca. La vía ingresa al lado chileno por el portezuelo de Tocorpuri (entre el cerro de Tocorpuri y el cerro Pajonal), continuando paralela por el norte de la pequeña quebrada Agua Brava. Luego conecta con Ojos de Putana hacia el suroeste en un eje recto de $8 \mathrm{~km}$ y desde aquí sigue otros $5 \mathrm{~km}$ hasta la Vega de Incahuasi. Hasta la localidad de Machuca hay una distancia de $10 \mathrm{~km}$ cuyo trayecto va por el sur del cerro Pabellón, atravesando Pampa Incahuasi donde predomina una superficie de ignimbrita con sectores de arenales. Al llegar a Machuca la vía entra por la quebrada Puritama, inmediatamente al oeste del cerro Falda Grande.

La parte intermedia de la vía, entre Machuca y Felon, cubre una distancia de $18 \mathrm{~km}$, desde los $4100 \mathrm{~m} . \mathrm{snm}$ hasta los $3200 \mathrm{~m} . \mathrm{snm}$. Saliendo de la laguna y vega de Machuca ocurre un cambio geomorfológico, dando inicio al Carcanal Gualcacasa, un relieve irregular con formación de pequeñas quebradas secas donde predominan la ignimbrita y una vegetación arbustiva. Desde aquí la vía continúa paralela al oeste de la quebrada Cueva Blanca hasta el sector Mal Paso a $3436 \mathrm{~m}$.snm, produciéndose la principal inflexión de la ruta, la cual evita el cruce de la quebrada de Caire. Luego, la vía transcurre por un sector arenoso de lomajes suaves entremezclado con sectores de ignimbrita hasta llegar a la quebrada de Felon.

En este tramo se identificó una amplia y dispersa fuente de obsidiana que debió originarse por las coladas de lavas del volcán Machuca y del domo Falda Grande. Las concentraciones más importantes las registramos cerca del cerro Machuca y Falda Grande y en pleno Carcanal de Gualcacasa, disminuyendo su tamaño y densidad de acuerdo a la gradiente altitudinal. Las únicas referencias sobre esta fuente las encontramos en De Souza y colaboradores (2002), quienes registran pequeños nódulos secundarios al interior de la quebrada de Felon, unos 15 $\mathrm{km}$ más abajo.

El tercery último tramo incluye los ramales Felon-Ghatchi y Felon-Calar. En éste, la vía atraviesa el Llano de Felon, un plano inclinado donde predomina en los primeros sectores la ignimbrita, y a medida que se avanza aparece un pedregal de rodados oscuros, con escasa o nula presencia de vegetación. Mientras en el primer sector la vía está muy bien conservada y con alta visibilidad, en el sector de pedregal la conservación y visibilidad es regular a mala, puesto que el típico "rastrillado" de los senderos tiende a perderse producto del arrastre natural de estos materiales.Aquí se desprende el ramal a Ghatchi, el cual cubre una distancia de $3.5 \mathrm{~km}$, desde los 2880 hasta los $2767 \mathrm{~m} . \mathrm{snm}$. Este trayecto continúa por el sur de Lomas Negras, atravesando la quebrada El Loro por un sector bajo de ésta, para conectar finalmente en un eje relativamente recto con el sitio Ghatchi-ıA, en la ribera noroeste del río Vilama. Se constata que una de las condicionantes topográficas que determinó que el eje vial fuese inmediatamente al sur de Lomas Negras, fue tanto el farellón natural de esta formación como el cruce de la quebrada El Loro, ya que ésta mientras más al sur se hace más profunda e inaccesible y más al norte implicaría necesariamente tener que atravesar el farellón de Lomas Negras.

Por su parte, el ramal a Calar se desprende un poco más al sur del ramal de Ghatchi, el cual cubre una distancia de 5.3 $\mathrm{km}$, desde los 2800 hasta los $2650 \mathrm{~m}$.snm, con un desnivel de $150 \mathrm{~m}$. Este segmento continúa en dirección sureste hasta la ladera oeste de la quebrada El Loro, pasando por lo alto del sitio habitacional y rupestre $02-\mathrm{Vi-90}$ (Montt 2006; Agüero y Uribe 2008). Sólo en este punto la vía posee amplia visibilidad, observándose las marcas de los senderos paralelos en la ladera de la quebrada. Desde ahí, el trayecto continúa por la ladera oeste del río Vilama hasta conectar finalmente con Calar en la ribera este.

Considerando la totalidad del trayecto, se observa que es una vía que tiende a la rectitud en su trazado, privilegia los sectores planos y evita el tránsito por el interior de las quebradas o el cruce de las mismas. Así se reducen potenciales situaciones de riesgo para los animales y para 
el viaje, aun cuando la distancia sea aparentemente más directa y corta (ver Nielsen 1997). Esto constituye una clara lógica de movilidad donde se privilegió el trazado por los sectores altos del relieve, para mantener alejados a los animales del forraje y tener un mayor control visual del entorno (Pimentel et al. 2007). Es una vía que conecta con cinco lugares con fuentes permanentes de agua:vega de Putana, vega de Incahuasi, Machuca, Felon y Vilama, teniendo una distancia máxima de $18 \mathrm{~km}$ sin este recurso. Es un trecho que puede ser recorrido en una jornada de viaje, y la disponibilidad de agua, forraje y leña no debió ser un inconveniente en todo el trayecto.

Sin embargo, los puntos con agua y abundante forraje muestran otro tipo de problema de difícil resolución arqueológica. Sabemos que estos lugares no sólo fueron ocupados transitoriamente por los grupos que participaron de la movilidad interregional, sino también utilizados por poblaciones locales de pastores que integraron dentro de sus circuitos de pastoreo las vegas de Putana, Incahuasi, Machuca y Felon. De hecho, hasta el día de hoy, todos estos espacios cuentan con estancias que son ocupadas por pastores principalmente de Machuca y Guatin. En consecuencia, si bien estos sectores debieron ser los principales lugares de alojamiento para los viajeros, también lo fueron y lo son para las poblaciones locales dentro del circuito de pastoreo. Esta coincidencia de actividades pastoriles locales y caravaneras ha sido discutida por distintos investigadores, dando cuenta de las dificultades existentes para diferenciar arqueológicamente ambas modalidades productivas (Berenguer 1994, 2004; Nielsen 1997). Un modo de resolver este problema es intentar discriminar los lugares potenciales de mayor exclusividad de la movilidad interregional, para lo cual se podría asumir que los sitios alejados de las fuentes de agua y sin recursos potenciales para el pastoreo se insertarían principalmente dentro de la movilidad interregional. Si bien pudieron existir otro tipo de actividades en este sector (p.e., caza de vicuñas), las evidencias arqueológicas debieron estar principalmente vinculadas con el tránsito entre ambas vertientes de la cordillera.

De acuerdo a esto, los lugares más exclusivos de la movilidad debieron ser los sectores altos en las inmediaciones del cerro Tocorpuri, por sus condiciones extremadamente frías y sin recursos importantes para el pastoreo y menos aún para la agricultura. Un segundo caso corresponde a la pampa desértica desde Felon hasta Ghatchi y Calar, ya que es un desierto casi absoluto sin posibilidades para la agricultura o el pastoreo, por lo que su principal uso debió estar ligado al tránsito, aunque ya no sólo exclusivamente interregional sino también local y regional. Por último, en el tramo entre Machuca y Felon la situación difiere de las anteriores ya que entre ambos puntos predomina el piso vegetacional conocido como tolar, siendo uno de los espacios más intensamente explotados para la actividad pastoril y, por lo tanto, con sitios que debieron ser ocupados para dicha producción.

\section{- Características viales del Período FORMATIVO}

Con la prospección de la vía de Tocorpuri se pudo precisar que los senderos troperos son característicos de esta ruta, con la excepción de seis pequeños segmentos de caminos formales en lugares muy acotados del transecto, con un ancho máximo de $4.50 \mathrm{~m}$ y despeje de piedras a ambos lados de la vía, los que debieron haber sido creados en momentos incaicos o históricos, con patrocinio institucional para su construcción y mantención (Pimentel et al. 2007).

Todos los otros sectores muestran exclusivamente senderos con visibilidad diferencial. En el tramo alto de Tocorpuri-Machuca, cuya erosión es más intensa, los senderos tienen escasa visibilidad quedando marcada por lo general una sola senda, perdiéndose completamente en algunos sectores la visibilidad de la vía. Otro espacio crítico es el pedregal de rodados oscuros del Llano de Felon, observándose allí solamente entre uno y tres senderos levemente marcados. Por su parte, los sectores mejor conservados de la vía se encuentran en las laderas de quebradas o cerros, contándose hasta seis sendas en el acceso norte a la vega de Putana (Tramo 1) y hasta 18 sendas sobre un pequeño lomaje en el sector de Mal Paso (Tramo 2, Figura 2.a). La vía presenta el mejor estado de conservación en los sectores de ignimbrita entre Machuca y Llano Felon (Figura 2.b), registrándose hasta 14 sendas paralelas con un ancho máximo de $22 \mathrm{~m}$. 
La vía es sinuosa y recta, con evidencias de superposición de sendas donde predominan en un corte transversal los surcos de forma cóncava. Los senderos no superan los $30 \mathrm{~cm}$ de ancho, mostrando distancias irregulares entre sendas (desde $40 \mathrm{~cm}$ hasta $5 \mathrm{~m}$ ) y en los puntos de mejor visibilidad se observa un sendero principal más marcado y, a ambos lados de él, otros surcos paralelos menos nítidos.

De acuerdo a estas características formales, no cabe duda alguna de que la vía se utilizó para el tránsito con recuas de llamas. Las sendas paralelas del tipo "rastrillado", con distancias irregulares entre ellas, surcos interconectados o superpuestos y un comportamiento en planta sinuoso, indican una movilidad caravanera con llamas. Pero, ies posible extrapolar estas evidencias de movilidad caravanera al Período Formativo y, en particular, a su época más temprana, considerando sobre todo que fue una ruta con uso continuo desde dicho período hasta tiempos históricos recientes? Para discutir este aspecto analizaremos con mayor detalle los ramales que conectaron con los asentamientos formativos de Ghatchi y Calar, al ser justamente los segmentos con mayor potencial diagnóstico para este período.

\section{* Conexiones con los asentamientos de Ghatchi y CALAR}

El ramal que se desprende de la vía de Tocorpuri en el Llano de Felon hacia el sector de Ghatchi muestra también visibilidad diferencial de los senderos, con un rango que varía desde evidencias mínimas, con un solo surco de $30 \mathrm{~cm}$ de ancho, hasta nueve sendas paralelas tipo "rastrillado" y anastomosados de $25 \mathrm{~m}$ de ancho (Tabla 1) que comparten las mismas características de los senderos paralelos identificados en la ruta de Tocorpuri, es decir, surcos sinuosos, de forma cóncava y con un eje relativamente recto (Figura 2.c).

En su acceso al sector de Ghatchi observamos una conexión directa con Ghatchi-1A, el asentamiento del sector que es considerado como el de mayor ocupación durante el Formativo Temprano (Agüero y Uribe 2008). Unos metros antes de la conexión con Ghatchi-1A, se desprende un ramal con dirección al sur, con senderos paralelos que comunican con los asentamientos de Ghatchi-2 (Figura 2.d). Esta vía sube por un pequeño lomaje, pasando por el lado oeste de los paneles rupestres O2-Vi163 y continuando por unos lomajes suaves al oeste de los sitios de Ghatchi-2 e inmediatamente al este de una pequeña quebrada seca, donde se observó una importante cantidad de sendas paralelas. Debemos señalar que en el sector de Ghatchi se identificaron también distintos ejes viales, siendo claramente un lugar donde confluyeron múltiples vías, principalmente locales.

Por su parte, el ramal a Calar muestra principalmente una sola senda, aunque en lugares muy acotados contabilizamos hasta 11 sendas con un ancho máximo de $23 \mathrm{~m}$ en la ladera oeste de la quebrada El Loro, justo sobre el sitio habitacional con arte rupestre 02-Vi-9o (Punto 4.1, Tabla 1; Figura 2.e). Por cierto, estas escasas evidencias indican la existencia de senderos troperos, pero los intensos procesos erosivos ocurridos en el sector de pedregal han borrado la mayor parte de ellos. De todos modos, los pocos casos de senderos troperos indican que fue una vía transitada con recuas de llamas. Además, a diferencia del ramal a Ghatchi, este segmento contribuye no sólo a la conexión con la aldea de Calar, ya que también se registraron sitios menores de descanso (paskanas o jaras) utilizados en el Período Formativo (Figura 2.f), indicando que este ramal tuvo una mayor intensidad de uso para dicha época.

En cuanto a las evidencias del tránsito de recuas de llamas en el ramal a Ghatchi y Calar, los senderos troperos paralelos, sinuosos y anastomosados son elementos contundentes en confirmar el paso de caravanas de llamas por este sector. Además, la relación directa con sitios que tuvieron una ocupación durante el Formativo sugiere que en dichos momentos la ruta ya era transitada por recuas de llamas cargueras. Si bien hay que considerar que tanto en el caso de Ghatchi-1A como en Calar hubo una reutilización durante el Período Intermedio Tardío (Agüero 2005; Adán y Urbina 2007) que pudo haber incidido en la creación o ampliación de los múltiples senderos paralelos. Sin embargo, estas evidencias parecen ser marginales y no representan ocupaciones relevantes. Por lo tanto, las características formales de la vía y su conexión directa con los asentamientos de Ghatchi y Calar constituyen antecedentes que permiten plantear la existencia en ambos ramales de una movilidad 

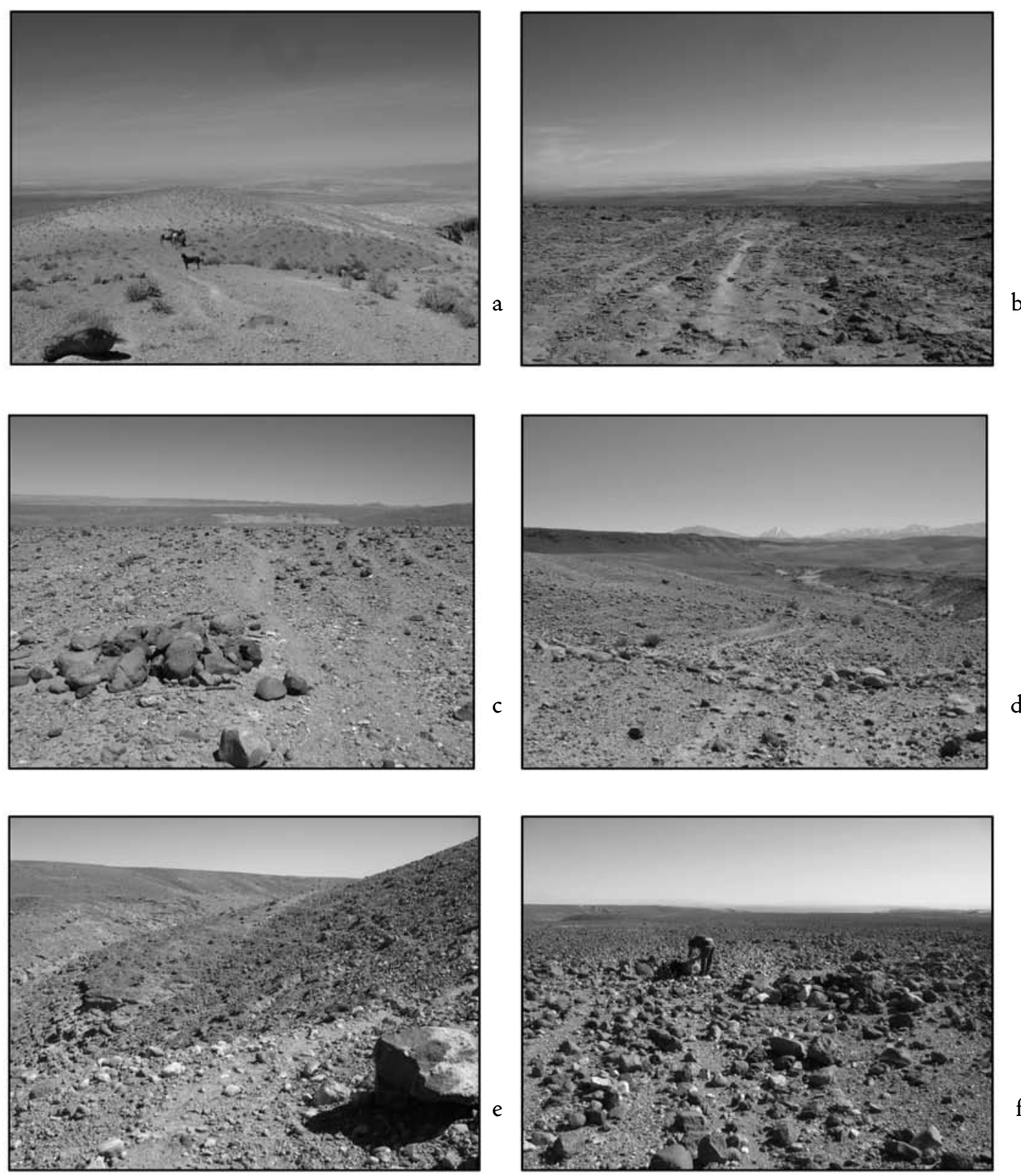

Figura 2. a) Vista de senderos tipo "rastrillado" en sector Mal Paso; b) Vista de senderos sobre roca de ignimbrita en Llano Felon;

c) Senderos junto a estructura de señalización ESFG-O2 en ramal a Ghatchi; $\mathbf{d}$ ) Vista de senderos que conectan el sitio de Ghatchi-2 con Ghatchi-1. Al fondo se observa Ghatchi-1A; e) Senderos en la parte alta del sitio habitacional y rupestre 02-Vi-90;

f) Evidencias de senderos y paskanas con materiales formativos (SHFCA-O4), en sector de pedregal del Llano Felon. 


\begin{tabular}{|c|c|c|c|c|c|c|c|}
\hline $\begin{array}{c}\mathrm{N}^{\circ} \\
\text { Punto }\end{array}$ & Tramo & UTM E & UTM N & Altura & $\begin{array}{l}\mathrm{N}^{\circ} \text { de } \\
\text { sendas }\end{array}$ & $\begin{array}{c}\text { Ancho } \\
\text { total }(\mathrm{m})\end{array}$ & Evidencias asociadas \\
\hline 1 & Ramal Ghatchi & 589000 & 7477501 & 2806 & 3 & 2.1 & ESFG-O1 \\
\hline 2 & Ramal Ghatchi & 588781 & 7477610 & 2807 & 2 & 1.8 & ESFG-O2 \\
\hline 3 & Ramal Ghatchi & 588992 & 7477552 & 2808 & 6 & 4.3 & ESFG-O3 \\
\hline 4 & Ramal Ghatchi & 588667 & 7477915 & 2809 & 5 & 4.8 & $\begin{array}{c}\text { Taller lítico }(5 \text { x } 5 \mathrm{~m} \text { ) láminas, } \\
\text { lascas y núcleos de basalto, } \\
\text { sílice y obsidiana }\end{array}$ \\
\hline 5 & Ramal Ghatchi & 588565 & 7478148 & 2828 & 9 & 25 & SHFG-O1 \\
\hline 6 & Ramal Ghatchi & 588394 & 7478263 & 2809 & 2 & 5 & Ramal con rumbo NE \\
\hline 7 & Ramal Ghatchi & 588441 & 7478641 & 2842 & 4 & 13 & ESFG-4 \\
\hline 8 & Ramal Ghatchi & 588398 & 7478945 & 2854 & 7 & 10 & ESFG-5 \\
\hline 9 & Ramal Ghatchi & 588403 & 7479092 & 2861 & 2 & 3 & ESFG-6 \\
\hline 10 & Ramal Ghatchi & 588461 & 7479279 & 2866 & 1 & 0.3 & SHFG-O2 \\
\hline 11 & Ramal Ghatchi & 588601 & 7479528 & 2875 & 1 & 0.3 & ESFG-7 \\
\hline 12 & Ramal Ghatchi & 588784 & 7479877 & 2880 & 3 & 3 & Conexión con ruta Tocorpuri \\
\hline 1 & Ramal Calar & 587142 & 7475491 & 2725 & 1 & 0.3 & ESFCA-O1 \\
\hline 2 & Ramal Calar & 587187 & 7475644 & 2723 & 1 & 0.3 & SHFCA-o1 \\
\hline 3 & Ramal Calar & 587281 & 7475823 & 2734 & 3 & 5 & SHFCA-O2 \\
\hline 4 & Ramal Calar & 587318 & 7475884 & 2724 & 1 & 0.3 & SHFCA-O3 \\
\hline 4.1 & Ramal Calar & 587349 & 7476036 & 2726 & 11 & 23 & Sector alto sitio O2-Vi-9O \\
\hline 5 & Ramal Calar & 587365 & 7477373 & 2801 & 2 & 5 & SHFCA-O4 \\
\hline 6 & Ramal Calar & 587995 & 7478506 & 2840 & 2 & 1 & SHFCA-O5 \\
\hline 7 & Ramal Calar & 588075 & 7479228 & 2853 & 1 & 0.3 & Conexión con ruta Tocorpuri \\
\hline
\end{tabular}

Tabla 1. Puntos en que se tomaron datos sobre la vía en los tramos de Ghatchi y Calar.

caravanera desde el Período Formativo. Retomaremos esta discusión al final.

\section{- Paskanas o jaras del Período Formativo}

En la prospección se identificaron 45 sitios habitacionales directamente asociados a la vía Tocorpuri-Catarpe, detectándose 27 casos con evidencias prehispánicas, 10 casos con ausencia de material cultural y ocho exclusivamente con materiales históricos. Por lo general se trata de sitios menores, bastante discretos y expeditivos, donde en 28 de ellos se aprovecharon los afloramientos rocosos o laderas de quebradas para levantar los campamentos. De los sitios prehispánicos, 15 entregaron evidencias diagnósticas que cubren un rango de ocupación desde el Período Formativo al Período Tardío (Pimentel et al. 2007). En este acápite se analizan los sitios con evidencias diagnósticas del Período Formativo del trayecto Tocorpuri-Llano Felon y, además, se agregan los nuevos sitios de descanso registrados en el ramal de Ghatchi y Calar (Tabla 2).

En la parte alta de la vía del sector de Tocorpuri, sobre los $4500 \mathrm{~m} . \mathrm{snm}$, se registraron los sitios habitacionales SHTM-03 y SHTM-o8, ambos con cerámica del Período Formativo. Estos campamentos se levantaron aprovechando la ladera rocosa sur de la pequeña quebrada Agua Brava. Comparte las características constructivas, con recintos menores de piedra, paramentos de hilada simple, muros desaplomados y aparejo rústico. El sitio SHTMo3 (Figura 3.a) se compone de cuatro recintos aglutinados con plantas de forma semicircular e irregular, sobre una superficie construida de $22.8 \mathrm{~m}^{2}$. Tanto en el interior y exterior de R1 como interior de R2 se registraron escasos fragmentos cerámicos del tipo Los Morros-A 


\begin{tabular}{|c|c|c|c|c|c|c|c|c|c|}
\hline Sitio & Sector & UTM E & UTM N & Altura & $\begin{array}{l}\mathrm{N}^{\circ} \\
\text { rec. }\end{array}$ & $\begin{array}{c}\mathrm{m}^{2} \\
\text { const. }\end{array}$ & Tipo planta & $\begin{array}{c}\text { Tipos } \\
\text { cerámicos }\end{array}$ & Lítico \\
\hline SHTM-O3 & $\begin{array}{l}\text { Paso de } \\
\text { Tocorpuri }\end{array}$ & 613473 & 7513691 & 4599 & 4 & 22.8 & $\begin{array}{l}\text { irregular y } \\
\text { semicircular }\end{array}$ & LMS-A, LRA & Mortero cónico \\
\hline SHTM-o8 & $\begin{array}{c}\text { Qda.Agua } \\
\text { Brava }\end{array}$ & 611590 & 7512691 & 4510 & 5 & 101.7 & $\begin{array}{c}\text { irregular, } \\
\text { subcirculary } \\
\text { subrectangular }\end{array}$ & $\begin{array}{c}\text { LMS-A, YAV- } \\
\text { CHC, TCA }\end{array}$ & Lascas sílice gris \\
\hline SHFG-O1 & $\begin{array}{l}\text { Ramal } \\
\text { Ghatchi }\end{array}$ & 588565 & 7478148 & 2828 & 2 & 7.78 & irregular & & $\begin{array}{l}\text { Lascas de basalto, } \\
\text { cuarzo y obsidiana }\end{array}$ \\
\hline SHFG-O2 & $\begin{array}{l}\text { Ramal } \\
\text { Ghatchi }\end{array}$ & 588461 & 7479279 & 2866 & 1 & 11.85 & irregular & TRA, TCA & $\begin{array}{c}\text { Lascas de } \\
\text { obsidiana y } \\
\text { basalto. Partículas } \\
\text { de mineral de } \\
\text { cobre }\end{array}$ \\
\hline SHFCA-O1 & $\begin{array}{l}\text { Ramal } \\
\text { Calar }\end{array}$ & 587187 & 7475644 & 2723 & 1 & 16.3 & irregular & LMS-B1 & $\begin{array}{l}\text { Lascas de basalto, } \\
\text { sílice y obsidiana }\end{array}$ \\
\hline SHFCA-O2 & $\begin{array}{l}\text { Ramal } \\
\text { Calar }\end{array}$ & 587281 & 7475823 & 2734 & 3 & 24.5 & $\begin{array}{l}\text { U, irregular, } \\
\text { semicircular }\end{array}$ & $\begin{array}{c}\text { LMS-B, TRA, } \\
\text { TCA }\end{array}$ & $\begin{array}{c}\text { Núcleos y lascas } \\
\text { de basalto y } \\
\text { obsidiana }\end{array}$ \\
\hline SHFCA-O3 & $\begin{array}{c}\text { Ramal } \\
\text { Calar }\end{array}$ & 587318 & 7475884 & 2724 & 2 & 61.88 & irregular & TCA & - \\
\hline SHFCA-O4 & $\begin{array}{l}\text { Ramal } \\
\text { Calar }\end{array}$ & 587365 & 7477373 & 2801 & 2 & 7.65 & subcircular & $\begin{array}{c}\text { LCA, LRA, SNP, } \\
\text { SRV, AIQ }\end{array}$ & Lascas de basalto \\
\hline SHFCA-05 & $\begin{array}{l}\text { Ramal } \\
\text { Calar }\end{array}$ & 587995 & 7478506 & 2840 & 2 & 3.65 & semicircular & $\begin{array}{l}\text { AIQ TRA, HED } \\
\text { o YAV }\end{array}$ & $\begin{array}{l}\text { Lascas de basalto, } \\
\text { sílice y obsidiana }\end{array}$ \\
\hline
\end{tabular}

Tabla 2. Sitios habitacionales formativos y nuevos sitios registrados en los ramales a Calar y Ghatchi.

(en adelante LMS-A) y del tipo Loa Rojo Alisado (en adelante LRA) (Figura 3.b), y un mortero de cavidad cónica típico de tiempos arcaicos, en el interior del R1 (Núñez 1992b). ${ }^{7}$

Por su parte, el sitio SHTM-o8 lo componen cinco recintos dispersos y dos adosados, con una superficie construida de $101.7 \mathrm{~m}^{2}$ y con plantas de forma irregular, subcircular y subrectangular, dentro de los cuales destaca $\mathrm{R} 5$ por encontrarse abovedada (con una superficie de $3.5 \mathrm{~m}^{2}$ ) (Figura 3.c). Justamente, en este recinto se registró la única evidencia del Período Formativo que consiste en un fragmento del tipo LMS-A, habiendo también evidencias de fogón y de cerámica histórica del tipo Turi Café Alisado (en adelante TCA), junto a restos de vidrio y goma. Además, tanto en $\mathrm{R} 2$ como en $\mathrm{R}_{3}$ se identificó cerámica foránea del tipo Yavi-Chicha (en adelante YAV-CHC) del Período Intermedio Tardío.

7 Para una descripción de los tipos cerámicos y su cronología, ver Uribe (2006).
De acuerdo a estas evidencias, este sitio fue ocupado desde tiempos formativos, siendo posteriormente reutilizado en los períodos Intermedio Tardío e Histórico.

Ya en el sector de Felon, se identificó el sitio SHMF-14, el cual se emplaza en la meseta norte de la quebrada homónima. Corresponde a una extensa área con 55 pequeños recintos no aglutinados de planta semicircular e irregular $y$, en menor grado, recintos de planta subrectangularyen forma de 'L'. Las únicas evidencias cerámicas del Período Formativo (alfarería LRA) se localizaron en R43, una estructura semicircular de muros bajos y con un diámetro máximo de $1.60 \mathrm{~m}$. Asociadas a este recinto se registraron escasas lascas líticas de basalto y un mortero cónico. Las otras evidencias cerámicas corresponden a los períodos Intermedio Tardío, Tardío e Histórico, constituyendo un espacio largamente reocupado en el tiempo. La dispersión de los recintos, el predominio de plantas semicirculares y la abundancia de morteros cónicos y de desechos líticos sobre una diversidad de materias primas (obsidiana, riodasita, basalto, sílice rojo y beige) sugieren que fue 
un sitio ocupado por poblaciones locales que utilizaron intensamente este sector desde el Arcaico, continuando en el Formativo y, en menor medida, vinculado con grupos en tránsito de los distintos períodos. Previamente esta área y en apariencia este mismo sitio ya habían sido reseñados por Le Paige (1964) quien recolectó más de 9800 piezas líticas, destacando las puntas tetragonales, que el autor vinculaba con el Tambillense o la transición al Mesolítico.

Entrando en el ramal que comunicó con Ghatchi se registró el sitio SHFG-ol, emplazado en lo alto de un lomaje al suroeste de la formación de Lomas Negras, a una altura de $2828 \mathrm{~m}$.snm. Corresponde a dos recintos de forma irregular y muros bajos, con una superficie construida de $7.78 \mathrm{~m}^{2}$. Tanto al interior como exterior de los recintos se registró una importante cantidad de lascas secundarias y núcleos sobre basalto, y en menor proporción sobre cuarzo y obsidiana. Otro sitio identificado es SHFG-O2, con cerámica de los tipos Turi Rojo Alisado (en adelante TRA) del Período Intermedio Tardío y TCA de tiempos históricos, además de tres pequeños desechos de obsidiana, una lasca de basalto y partículas de mineral de cobre. En ninguno de los dos sitios se registraron indicadores materiales propios del Período Formativo.

La situación del ramal a Calar difiere del caso anterior, ya que aquí hubo evidencias de ocupación durante el Período Formativo, y además de los períodos Medio, Intermedio Tardío e Histórico. Por ahora, nos referimos a los sitios con evidencias prehispánicas, excluyendo al sitio SHFCA-O3, el único con registros exclusivamente históricos.

El sitio SHFCA-or se emplaza en lo alto de un sector de lomajes en la meseta oeste del río Vilama, a una altura de 2723 m.snm (Figura 3.d). Corresponde a una estructura incierta que preliminarmente hemos considerado habitacional, ya que posee un área despejada asociada a gran cantidad de material lítico y a algunos fragmentos cerámicos. Se trata de una superposición irregular de rodados oscuros de tamaño mediano adosados a un gran bloque rocoso, en una superficie de $16.30 \mathrm{~m}^{2}$. A su alrededor se registraron más de 100 lascas líticas, principalmente sobre basalto, sílice y en menor medida sobre obsidiana, y cuatro fragmentos de cerámica formativa del tipo Los Morros-Bi (LMS-B1).

El sitio SHFCA-O2 posee el mismo emplazamiento que el sitio anterior, estando ubicado a unos $200 \mathrm{~m}$ al norte de aquel y a una altura de $2734 \mathrm{~m} . \mathrm{snm}$ (Figura 3.e). Corresponde a tres recintos dispersos, con una superficie construida de $24.5 \mathrm{~m}^{2}$, de aparejo rústico y con planta de forma en ' $U$ ', irregulary semicircular. Salvo Rı, con muros dobles, división interna con lajas verticales y un poyo, los otros dos recintos son de hilada simple, no observándose otros rasgos constructivos. De los materiales asociados, en $\mathrm{R} 1$ registramos un núcleo, alrededor de 10 lascas de basalto y escasos desechos secundarios de obsidiana, junto a cerámica de los tipos TRA del Intermedio Tardío y TCA de momentos históricos. En R2 se observó una lasca pequeña de obsidiana, mientras que en $R_{3}$, una estructura semicircular de $5.5 \mathrm{~m}^{2}$ de superficie, se registraron ocho fragmentos cerámicos del tipo LMS-Br y escasas lascas secundarias de basalto.

Por su parte, el sitio SHFCA-o4 se emplaza en un sector de pedregal en el Llano de Felon, a una altura de 2801 m.snm. Se trata de dos recintos subcirculares no aglutinados con una superficie total de $7.65 \mathrm{~m}^{2}$. El Ri posee una superficie de $3.91 \mathrm{~m}^{2}$, con muros construidos con rodados de tamaño mediano, hilada doble, aplomados y aparejo rústico (Figura 4.f). Tanto en su interior como exterior se registraron fragmentos cerámicos de los tipos LCA $(n=4)$ y LRA $(n=1)$ del Período Formativo, y más de 100 lascas líticas pequeñas y medianas de basalto. También se identificaron fragmentos de los tipos San Pedro Negro Pulido (en adelante SNP) del Período Medio, San Pedro Rojo Violáceo (en adelante SRV) y Aiquina (en adelante AIQ) propios del Período Intermedio Tardío. Por su parte, R2 con una superficie de $3.74 \mathrm{~m}^{2}$ y paramentos de hilada simple, entregó 15 lascas secundarias de basalto. De acuerdo a esto, la ocupación de este sitio se inició en el Formativo, reutilizándose en los períodos Medio e Intermedio Tardío.

Por último, el sitio SHFCA-05 también se localiza en el pedregal del Llano Felon, a una altura de 2840 m.snm. Cuenta con dos estructuras separadas, de planta semicircular, 

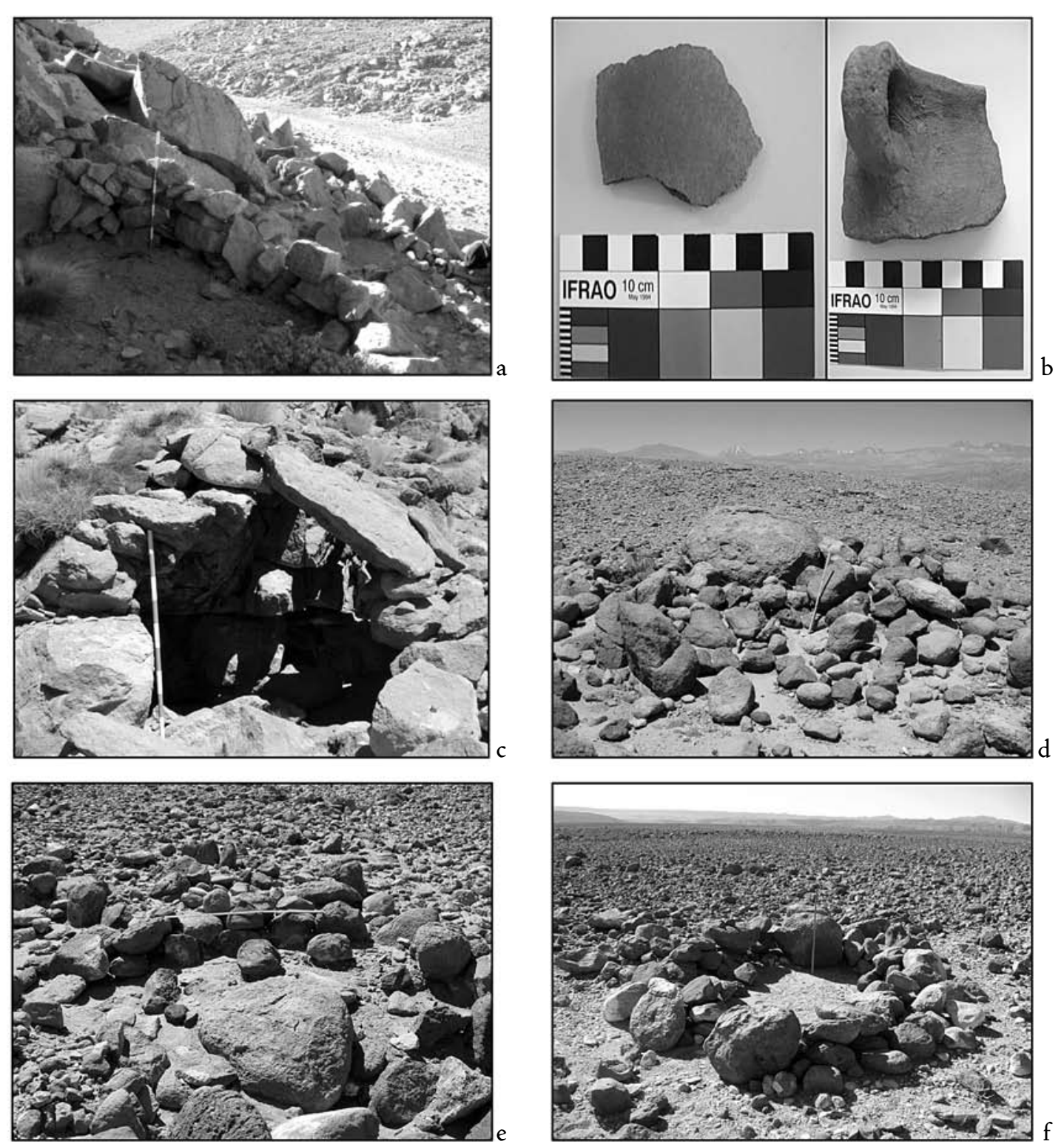

Figura 3. a) Paskana SHTM-o3 en parte alta de la vía, sector Tocorpuri; b) Cerámica formativa tipos Los Morros y Loa Rojo Alisado encontrada en sitio SHTM-O3; c) Detalle de estructura abovedada del sitio SHTM-o8 (Recinto 5); d) Vista del sitio SHFCA-O1 Con cerámica del Período Formativo; e) Vista del sitio SHFCA-O2 (Recinto 3); f) Vista del sitio SHFCA-O4 (Recinto 1).

hilada simpley una superficie construida de $3.65 \mathrm{~m}^{2}$. Aquí no registramos indicadores del Período Formativo, sino únicamente fragmentos cerámicos del Intermedio Tardío (tipos AIQ, TRAy un posible Yavi o Hedionda).

En síntesis, estos antecedentes indican que la ruta de Tocorpuri fue utilizada a lo menos desde tiempos formativos y con continuidad en toda la secuencia prehispánica, con evidencias habitacionales formativas distribuidas en todo el transecto. La presencia de sitios menores que en general no superan los $101 \mathrm{~m}^{2}$, de factura expeditiva, con escasa cerámica y líticos, junto a la estrecha relación con la vía de circulación, permite precisar su contexto de uso. Con 
la excepción del sitio SHMF-14 que posee elementos contextuales suficientes como para asumir que fue una ocupación local, todos los demás cumplen con los requisitos para definirlos como paskanas o jaras, es decir, campamentos de descanso en contextos de movilidad interregional.

Del mismo modo, el registro superficial de cerámica diagnóstica del Formativo en cinco sitios (SHTM-O3, SHTM-o8, SHFCA-O1, SHFCA-O2 y SHFCA-04) es relevante para aproximarse a las características de las paskanas de dicho período. De ellos, son casos ideales los sitios SHTM-03, SHFCA-or y SHFCA-o2, ya que los dos primeros muestran una ocupación monocomponente del Período Formativo, y SHFCA-O2, si bien fue reutilizado en tiempos posteriores, las ocupaciones se observaron diferenciadas por recintos, constatándose en $\mathrm{R}_{3}$ una ocupación exclusiva del Formativo. De tal manera, considerando estos campamentos se puede apreciar que son sitios que cuentan con un máximo de cuatro recintos, con plantas de forma semicircular e irregular, que no sobrepasaron los $23 \mathrm{~m}^{2}$. A nivel de recinto, excluyendo el recinto incierto de SHFCA-o1, las estructuras más amplias no superan los $8 \mathrm{~m}^{2}$ (SHTM-o3 $\mathrm{R} 1)$, mientras que lo más característico son los recintos menores que van desde $5.5 \mathrm{~m}^{2}$ (SHFCA-O2 $\mathrm{R}_{3}$ ) hasta los más pequeños con $1.5 \mathrm{~m}^{2}$ (SHTM-03 R2), en cuyo caso intermedio permitiría alojar a una o, cuando más, a dos personas.

No es un dato menor que de los cinco sitios con algún tipo de evidencias formativas, tres de ellos se concentran en el ramal a Calar, es decir, en un pequeño segmento de sólo $5.5 \mathrm{~km}$. Esto confirma la mayor intensidad de uso, aunque no exclusiva, de este ramal en tiempos formativos, ya que la relación entre evidencias de éste y de otros períodos es superada ampliamente por las ocupaciones tempranas. En efecto, con la excepción del sitio SHFCA-O3, sin evidencias formativas pero sí de los períodos Medio e Intermedio Tardío, todos los demás sitios mostraron el inicio de ocupación en el Formativo con posteriores reutilizaciones, ya sea en el Período Medio, Intermedio Tardío y/o Histórico. Por otra parte, la casi total ausencia de paskanas con evidencias del Formativo en el ramal a Ghatchi se explicaría por la corta distancia de $3.3 \mathrm{~km}$ entre el desvío del ramal y la conexión con el asentamiento Ghatchi-1A, siendo un trayecto corto que no implicaría la necesidad de alojar en puntos intermedios.

En relación al emplazamiento y espaciamiento de las paskanas, precisábamos anteriormente que si se considera la totalidad de sitios habitacionales prehispánicos entre Tocorpuri y Felon, encontramos este tipo de sitios en casi la totalidad del trayecto, con una distancia máxima de $5 \mathrm{~km}$ entre ellos, dando un promedio de un sitio por cada $1.3 \mathrm{~km}$ (Pimentel et al. 2007). De esta manera, los campamentos de descanso no se restringen a los puntos más favorables, con agua y buen forraje, puesto que también están en sectores sin estos recursos básicos. Para el caso de los sitios con evidencias formativas se observó una concentración tanto en la parte alta de la ruta (sector de Tocorpuri), con dos sitios, como en el ramal a Calar, con tres sitios. La distancia mínima entre ellos es de $203 \mathrm{~m}$ para el caso de Calar (entre SHFCA-O1 y SHFCA-O2) y de $2.17 \mathrm{~km}$ para el caso de Tocorpuri (entre SHTM-03 y SHTM-o8), mostrando que ambas situaciones correspondieron a un mismo sector de campamentos de descanso dentro de una misma jornada, que por algún motivo, que aún desconocemos, no se concentraron en un mismo punto. En cambio, la distancia máxima entre las evidencias de campamentos formativos es de $36.6 \mathrm{~km}$ (entre SHMF-14 y SHTM-o8), lo que corresponde a un trecho bastante largo para una jornada de (Tabla 3 ) viaje. ${ }^{8}$ Por lo tanto, debieron existir paraderos de descanso intermedio entre ambos puntos, que de acuerdo a las distancias y disponibilidad de agua, debieron estar en la vega de Machuca. ${ }^{?}$

\footnotetext{
8 Se ha señalado que una jornada de viaje con recuas de llamas implicaría un recorrido de entre 15 y $25 \mathrm{~km}$ diarios (Berenguer 2004; Nielsen 2006).Y aun cuando un ser humano, sin llevar animales, puede recorrer ese trayecto en una jornada, esto necesariamente implicaría un sobreesfuerzo que no podría ser sostenido en el transcurso de varios días de viaje.

9 La distancia entre el sitio SHTM-o8 y Machuca es de 19 km, es decir, un trayecto que puede ser realizado en una jornada de viaje.
} 


\begin{tabular}{|l|c|}
\hline \multicolumn{1}{|c|}{ Sitios habitacionales } & Distancia en $\mathbf{~ k m}$ \\
\hline SHTM-03 y SHTM-08 & 2.17 \\
\hline SHTM-08 y SHMF-14 & 36.6 \\
\hline SHMF-14 y SHFCA-04 & 9.27 \\
\hline SHFCA-04 y SHFCA-O2 & 1.57 \\
\hline SHFCA-02 y SHFCA-O1 & 0.203 \\
\hline
\end{tabular}

Tabla 3. Distancias entre sitios habitacionales con evidencias formativas.

Resulta interesante que los sitios formativos, al igual que la mayoría de los de períodos posteriores, no se reducen a los puntos con fuentes permanentes de agua como era lo esperable. Al contrario, la mayoría se localizó alejada de estos espacios privilegiados. Las explicaciones para esto pueden ser variadas, pero al parecer tienen una relación con respetar una territorialidad local de control sobre estas fuentes de aprovisionamiento.

\section{- Estructuras de señalización y eVidencias CEREMONIALES DEL Formativo}

Además de estructuras de alojamiento se registró una importante cantidad de estructuras de señalización simples que fueron exclusivamente marcadores viales. Poseen por lo general intervisibilidad entre ellas, implicaron baja inversión de trabajo y son baja altura, producto del apilamiento de pocas piedras, aunque en algunos casos se dispusieron sobre bloques rocosos grandes para permitir una mayor visibilidad. Cabe hacer la distinción de las estructuras clásicamente conocidas como apachetas, las cuales son construcciones dinámicas producto del lanzamiento intermitente de piedras que conformaron en el tiempo amplios montículos piramidales irregulares. Si bien las apachetas cuentan con una alta visibilidad pudiendo ser consideradas estructuras de señalización, también es claro que no se limitan a esta función, ya que ante todo representan una fuerte ritualidad en aquellos espacios que los viajeros consideraron sacralizados o simbólicamente significativos (ver Hyslop 1984; Vitry 2002; Berenguer et al. 2005).

En todo el trayecto entre Tocorpuri y Ghatchi-Calar se identificaron 32 estructuras simples de señalización. De acuerdo a cada tramo, la mayor cantidad se identificó en el Tramo $1(n=16)$, seguido por el Tramo $2(n=8)$, ramal a Ghatchi $(n=7)$ y la menor cantidad en el ramal a Calar $(\mathrm{n}=1)$, dando una distancia mínima entre ellas de $322 \mathrm{~m}$ en Pampa Incahuasi y una distancia máxima de $4.5 \mathrm{~km}$ en Ojos de Putana. En tal sentido, hay zonas con una mayor concentración de estas estructuras en Pampa Incahuasi, Mal Paso y Felon Sur, que consecuentemente son los sectores menos favorables respecto a la visibilidad y actual conservación de la vía (Tabla 3).

Las escasas evidencias materiales asociadas a estas estructuras simples se registraron en ocho casos: en tres (ESTM-11, ESTM-12, ESMF-04) se identificaron algunas lascas secundarias sobre obsidiana, en un caso (ESTM-15) se registraron semillas de chañar (Geoffrea decorticans) carbonizadas, y en ESMF-6 se identificó un fragmento del tipo TCA de momentos históricos. Por su parte, en el ramal a Ghatchi se consignaron lascas pequeñas secundarias de obsidiana y basalto asociadas a las estructuras ESFG-04, ESFG-05 y ESFG-07 (Tabla 4).

Estos datos, aunque limitados, sugieren que algunas de estas estructuras simples de señalización podrían haber sido parte del paisaje prehispánico en las rutas interregionales. La presencia escasa pero aclaratoria de material lítico asociado a cuatro de estas estructuras sugiere que existían en tiempos prehispánicos.

Para la categoría apacheta hemos distinguido dos clases de estructuras: 1) montículos de rocas que se realizaron al interior de pequeñas oquedades, sobre bloques rocosos de gran tamaño o adyacentes a bloques de mediano tamaño, las cuales también son producto del intermitente proceso de lanzamiento y acumulación de piedras. No obstante, a diferencia de las apachetas más características, en ellos no se observó un fuerte componente ceremonial, a juzgar por la ausencia de otros materiales culturales (p.e., cerámica, lítico, mineral de cobre) y de otras estructuras menores asociadas. Dentro de esta modalidad se registró una apacheta en un pequeño alero en el sector de Gualcacasa (ESMF O2), y otro caso cercano al anterior se encontró contiguo a un bloque rocoso de tamaño mediano (ESMF-O3). 


\begin{tabular}{|c|c|c|c|c|c|c|}
\hline Sector & Sitio & UTME & UTMN & Altura & Tipo General & Materiales asociados \\
\hline Qda.Aguas Bravas & ESTM-o1 & 612548 & 7513201 & 4569 & señalización simple & \\
\hline Qda.Aguas Bravas & ESTM-O2 & 611271 & 7512426 & 4496 & señalización simple & \\
\hline Qda.Aguas Bravas & ESTM-O3 & 610353 & 7511832 & 4466 & señalización simple & \\
\hline Ojos de Putana & ESTM-O4 & 606130 & 7510070 & 4421 & señalización simple & \\
\hline Ojos de Putana & ESTM-O5 & 606130 & 7510070 & 4421 & señalización simple & \\
\hline Vega de Incahuasi & ESTM-o6 & 604473 & 7508231 & 4390 & señalización simple & \\
\hline Pampa de Incahuasi & ESTM-O7 & 603093 & 7506892 & 4275 & señalización simple & \\
\hline Pampa de Incahuasi & ESTM-o 8 & 603093 & 7506892 & 4275 & señalización simple & \\
\hline Incahuasi & ESTM-O9 & 601894 & 7505628 & 4277 & señalización simple & \\
\hline Incahuasi & ESTM-10 & 601867 & 7505563 & 4291 & señalización simple & \\
\hline Incahuasi & ESTM-11 & 601634 & 7505316 & 4304 & señalización simple & Lascas de obsidiana \\
\hline Incahuasi & ESTM-12 & 601474 & 7505116 & 4309 & señalización simple & Lascas de obsidiana \\
\hline Incahuasi & ESTM-13 & 601157 & 7504738 & 4321 & señalización simple & \\
\hline Incahuasi & ESTM-14 & 600766 & 7504237 & 4325 & apacheta & Tipo cerámico TRB \\
\hline Pampa de Incahuasi & ESTM-15 & 600717 & 7504233 & 4337 & señalización simple & Chañar \\
\hline Pampa de Incahuasi & ESTM-16 & 600233 & 7503979 & 4314 & señalización simple & \\
\hline Pampa de Incahuasi & ESTM-17 & 599686 & 7503728 & 4298 & señalización simple & \\
\hline Machuca & ESMF-O1 & 597360 & 7497435 & 4010 & señalización simple & \\
\hline Apacheta & SCMF-2 & 596093 & 7495428 & 4055 & apacheta y "cargas" & $\begin{array}{l}\text { Lascas de obsidiana, sílice café y } \\
\text { basalto; tipos cerámicos LMS-A } \\
\text { SNP, TRA, TCA, HIS; chañar, } \\
\text { mineral de cobre, vidrio }\end{array}$ \\
\hline Gualcacasa & ESMF-O2 & 595516 & 7494874 & 4006 & apacheta & \\
\hline Gualcacasa & ESMF-O3 & 595332 & 7494756 & 4000 & apacheta & \\
\hline Gualcacasa & ESMF-O4 & 593946 & 7490695 & 3674 & señalización simple & Lascas de obsidiana \\
\hline Gualcacasa & ESMF-05 & 593723 & 7490223 & 3628 & señalización simple & \\
\hline Gualcacasa & ESMF-o6 & 593548 & 7489845 & 3586 & señalización simple & Tipo cerámico TCA \\
\hline Mal Paso & ESMF-07 & 593166 & 7489113 & 3517 & señalización simple & \\
\hline Mal Paso & ESMF-o8 & 593156 & 7489110 & 3517 & señalización simple & \\
\hline Mal Paso & ESMF-O9 & 593156 & 7489105 & 3517 & señalización simple & \\
\hline Mal Paso & ESMF-10 & 592011 & 7486003 & 3296 & señalización simple & \\
\hline Ramal Ghatchi & ESFG-O1 & 589000 & 7477501 & 2806 & señalización simple & \\
\hline Ramal Ghatchi & ESFG-O2 & 588781 & 7477610 & 2807 & señalización simple & \\
\hline Ramal Ghatchi & ESFG-03 & 588992 & 7477552 & 2808 & señalización simple & \\
\hline Ramal Ghatchi & ESFG-O4 & 588441 & 7478641 & 2842 & señalización simple & Lascas de basalto \\
\hline Ramal Ghatchi & ESFG-05 & 588398 & 7478945 & 2854 & señalización simple & $\begin{array}{l}\text { Lascas de basalto, nódulos de } \\
\text { obsidiana }\end{array}$ \\
\hline Ramal Ghatchi & ESFG-06 & 588403 & 7479092 & 2861 & señalización simple & \\
\hline Ramal Ghatchi & ESFG-07 & 588601 & 7479528 & 2875 & señalización simple & Lascas de obsidiana y sílice \\
\hline Ramal Calar & ESFCA-1 & 587142 & 7475491 & 2725 & señalización simple & \\
\hline
\end{tabular}

Tabla 4. Estructuras de señalización y apachetas asociadas a la ruta de Tocorpuri. 
2) También se registraron dos apachetas del patrón clásico en el primero y segundo tramo de la ruta. Una primera se identificó en plena Pampa Incahuasi (ESTM14) a 4325 $\mathrm{m} . \mathrm{snm}$, registrándose en la superficie cuatro fragmentos cerámicos del tipo TRB del Período Intermedio Tardío, y materiales subactuales como vidrio, latas de cerveza y aguardiente boliviano (pusitunga), lo que indica que ha seguido siendo reactivada en el último tiempo.

El otro caso corresponde al sitio Apacheta de Machuca (SCMF-O2), siendo la estructura ritual de mayor tamaño en la ruta (Figura 4.a). Se encuentra a $4055 \mathrm{~m} . \mathrm{snm}$ en un espacio que marca el cambio entre lomajes suaves y el carcanal de Gualcacasa, ubicado inmediatamente al oeste de la vía. Se trata de un gran amontonamiento de rocas de forma piramidal irregular de $3.60 \mathrm{~m}$ de altura y 7.90 de ancho máximo. Alrededor de ella y a ambos lados de la vía se construyó una considerable cantidad de pequeñas hileras de piedras ( $n=240)$, que los lugareños de Machuca denominan "cargas" (Figura 4.b).

Su emplazamiento indica la estrecha relación que tiene con el paisaje: se ubica en un espacio transicional donde se inician cambios geomorfológicos de un sector de lomajes a otro irregular de carcanal de ignimbrita y desde el cual se posee una amplia visibilidad del entorno. Desde el norte es el primer punto de la vía donde se observan los oasis de San Pedro, y desde allí se tiene una panorámica del conjunto de cerros y volcanes de la zona, lo cual seguramente explica la disposición y ritualidad de la apacheta. A ello se suma la existencia de una fuente de obsidiana ubicada en una hoyada inmediatamente al norte de la apacheta, incluso siendo halladas lascas de obsidiana o pequeños agrupamientos de nódulos (Figuras 4.cy 4.d) en directa asociación a la estructura principal y "cargas". Antecedentes de esta práctica han sido hallados en un

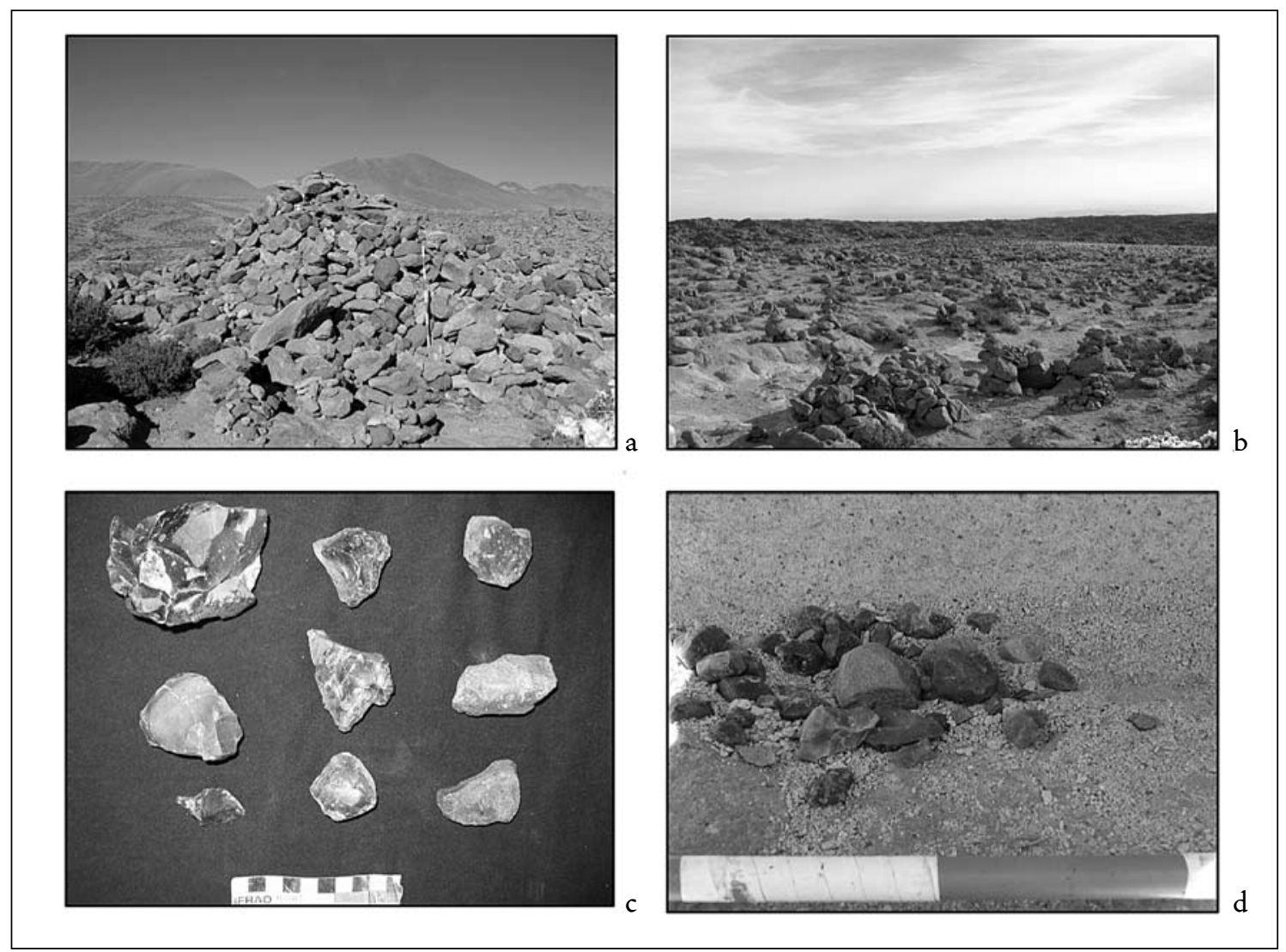

Figura 4. a) Detalle de la estructura tipo apacheta (sitio SCMF-O2); b) Vista general de las estructuras tipo "cargas" asociadas a la Apacheta de Machuca (Sitio SCMF-02);c) Nódulos procedentes de la fuente de obsidiana de Machuca; d) Concentración de guijarros dejados como ofrendas en la Apacheta de Machuca (SCMF-O2). 
sector que marca la entrada a Macchu Picchu, también con concentraciones de guijarros de obsidiana dejados como ofrendas (Burger 2006: 249). Estas pequeñas hileras de piedras o "cargas", por lo general poseen la misma orientación del eje vial, siendo construidas con pocas piedras que no superaron $1 \mathrm{~m}$ de alto y $1.50 \mathrm{~m}$ de largo. Como materiales asociados se registraron lascas líticas primarias y secundarias de obsidiana, sílice café y basalto, partículas de mineral de cobre, semillas de chañar, fragmentos de cerámica formativa (LMS-A), y de

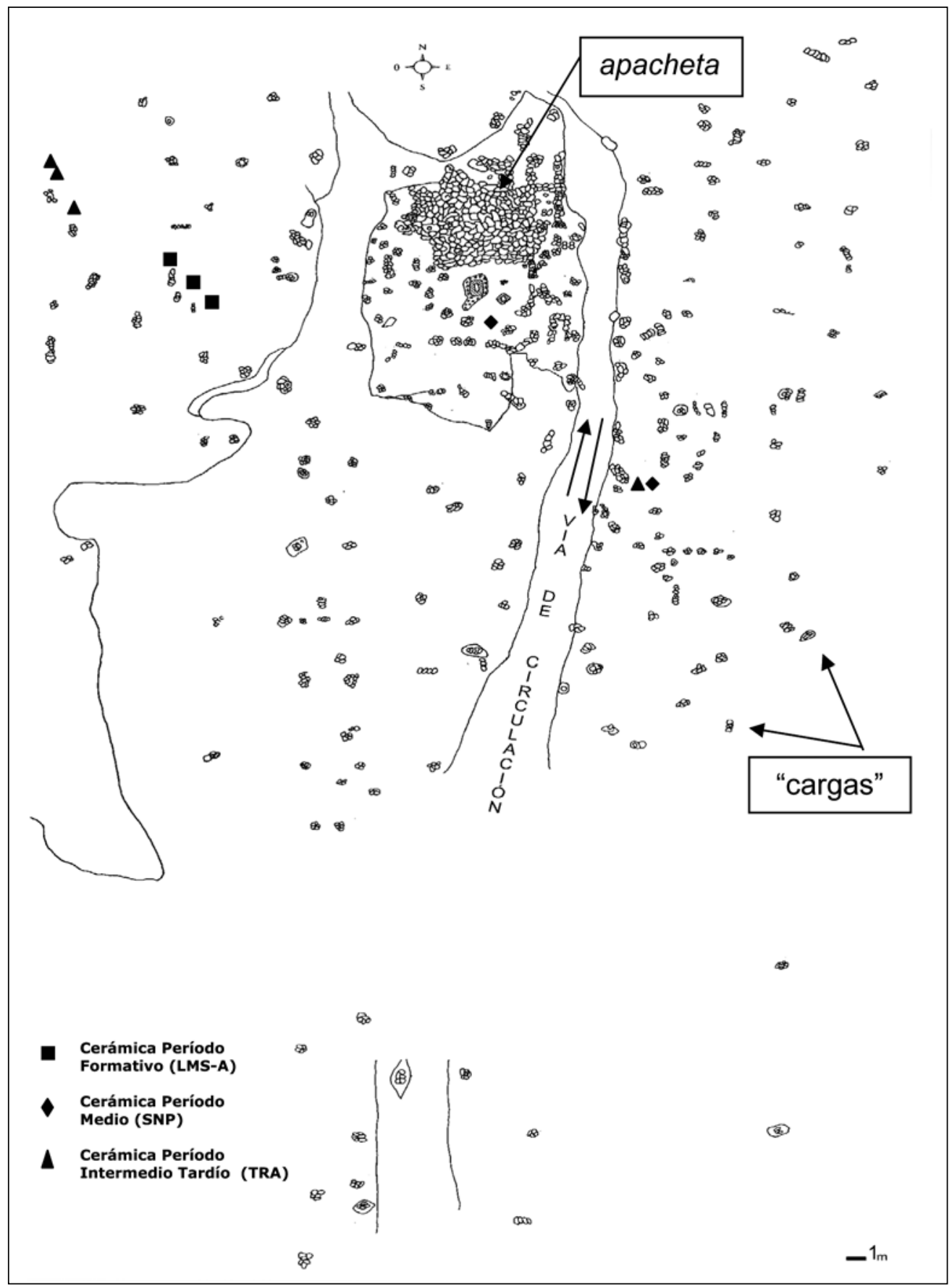

Figura 5. Dibujo de planta del sitio ceremonial Apacheta de Machuca (SCMF-O2) y distribución de la alfarería prehispánica recolectada. Dibujo: Paulina Chávez. 
los períodos Medio (SNP) e Intermedio Tardío (TRA); también materiales históricos como vidrio, latas de alcohol y cerámica de los tipos TCA e HIS. La cerámica formativa se registró exclusivamente en relación a las estructuras tipo "cargas", en la porción noroeste del sitio, lo que parece indicar el sector utilizado durante ese período (Figura 5).

Los relatos actuales proporcionan datos para comprender los significados de la ceremonia de la apacheta y "cargas". Los lugareños de Machuca cuentan que hasta la década de 1960 se veían pasar las caravanas que venían de Bolivia, siendo la apacheta una parada obligatoria para todos los viajeros. Allí se realizaban dos tipos de actividades: 1) una consistía en lanzar piedras al gran montículo pidiendo los "deseos" para un buen viaje y favorable intercambio; y otra en que cada viajero realizaba su propia "carga", en la que el número total de piedras representaba el número de animales de la caravana. En la actualidad, el sitio continúa siendo ocupado para actividades ceremoniales, pero ahora exclusivamente por parte de la comunidad de Machuca cuyos miembros realizan todos los años la ceremonia de ofrendar agua de mar en el lugar para pedir mayor abundancia de lluvias.

Relatos parecidos hemos registrado en la frontera entre la I y II Región de Chile, donde el ritual de la apacheta consistía en frotarse las piedras por las partes del cuerpo que estén más cansadas o afectadas por el viaje, para luego lanzarlas al montículo, como una manera de sacar el malestar físico. En este sentido, las piedras de la apacheta serían depositarias del cansancio de los viajeros, mientras que a las estructuras como las "cargas" las denominan "almacenes" y tendrían también una función distinta, ya que no representan el número de animales que compone la caravana, sino que se realizan para "pedir" por el favorable intercambio de los productos con que se pretende regresar.

Ambos tipos de situaciones han sido descritos por distintos investigadores andinos, es decir, tanto para alejar el cansancio, pedir protección y permiso para transitar por un nuevo espacio (p.e., Galdames 1990) como para un tener un favorable intercambio (p.e., Van Kessel 1992; Berenguer 2004). De esta manera, es claro que las apachetas fueron instalaciones ceremoniales y auspiciatorias insertas en las prácticas de la movilidad interregional, cuyo ritual consistía en pedir fundamentalmente por estos dos aspectos: tránsito y bienes de intercambio. Así, se podría intuir que al ser las expectativas más básicas de la movilidad interregional, pudieron ser también los elementos principales en el ritual de la apacheta en momentos prehispánicos. Como correlato arqueológico, los materiales cerámicos, líticos y mineral de cobre, entre otros, pudieron corresponder a algunos de los bienes ofrendados con el fin de tener una buena travesía o como expresión de los "deseos" de los viajeros para el intercambio de bienes.

Otro tipo de evidencias ceremoniales relacionadas a la vía fueron las representaciones rupestres. Hay que señalar que en todo el trayecto los únicos registros de este tipo se encuentran en la conexión a la meseta de Ghatchi-2 (O2-Vi-163 y 02-Vi-83) y en el ramal a Calar (O2-Vi-9O) ${ }^{10}$, lo que indica una fuerte regularización de los espacios que estaban destinados a este tipo de manifestación. Los primeros sitios poseen una buena visibilidad desde el ramal que conecta los sitios de Ghatchi-I con Ghatchi-2, así como en el cruce del río Vilama que se da entre ambos sitios con arte rupestre. En relación a o2-Vi-163, la ruta pasa por lo alto de este sitio, siendo observado sólo desde un trayecto de sur a norte, vale decir, desde los sitios de Ghatchi-2 a la meseta de Ghatchi-1. Por su parte, el sitio o2-Vi-83 posee visibilidad en ambos sentidos, ya que si bien se encuentran en la ladera opuesta al eje de tránsito, los grabados son de gran tamaño permitiendo que sean vistos desde el otro extremo de la quebrada. En ambos sitios hay paneles de la serie estilística Taira-Tulan (Montt 2006) que ha sido asignada al Período Formativo Temprano. Asimismo, en O2-Vi-163 se identificaron motivos "escutiformes" de tamaño pequeño propio de los períodos tardíos y que solamente son visibles en las inmediaciones del sitio, lo que indica su reutilización en tiempos tardíos.

\footnotetext{
10 Estos sitios han sido descritos y contextualizados por Montt (2006), por lo que para los fines de este artículo me limito a establecer la relación e intervisibilidad entre las representaciones rupestres y las vías de circulación prospectadas.
} 
En el caso del ramal a Calar, la vía pasa por la parte alta del sitio habitacional y rupestre o2-Vi90, ubicado en la seca y estrecha quebrada El Loro (Figura 6). Desde la ruta no se observan los paneles centrales del sitio ya que están en el farellón bajo la vía. De todos modos, desde este punto se tiene clara visibilidad del exclusivo panel que se encuentra en la ladera este de la quebrada (Panel 24, Figura 7), correspondiendo a la única evidencia de pictograbados en el sitio con representaciones de camélidos naturalistas del estilo Taira-Tulan (Montt 2006). Hay que precisar que unos metros más al sur hay una bajada a la quebrada El Loro, por lo que en dicho punto debió darse la conexión con el sitio o2-Vi-9o, siendo seguramente parte del sistema de sitios de descanso. Al respecto y dada la evidente improductividad de esta quebrada, se sugiere preliminarmente

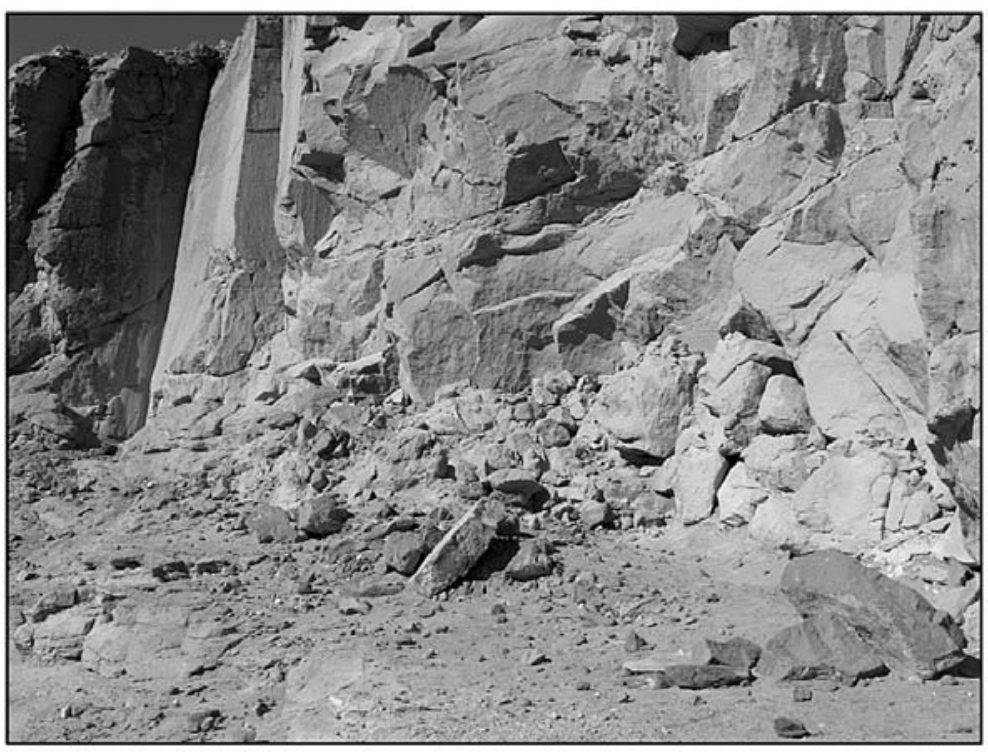

Figura 6. Vista general del sitio rupestre y habitacional o2-Vi-9o.

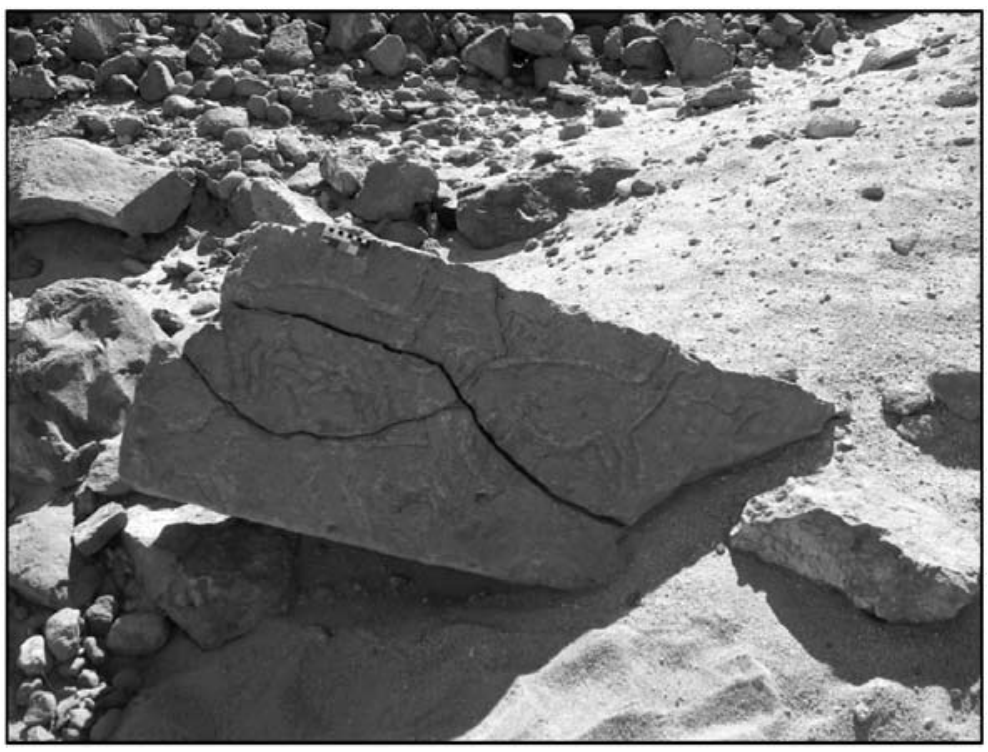

Figura 7. Detalle del panel 24 del sitio o2-Vi-9o con pictograbado de camélidos naturalistas de la serie estilística Taira-Tulan. 
que este sitio estuvo inserto en un contexto de movilidad interregional, lo que de acuerdo a los análisis estratigráficos y cronométricos se adscribe a la transición Arcaico Tardío-Formativo Temprano, con un rango de ocupación que va desde $3685 \pm 50 \mathrm{AP}(2204-1930 \mathrm{cal}$. AC) para el inicio de ocupación y $3190 \pm 55 \mathrm{AP}(1531-1392 \mathrm{cal}$. AC) para el techo de la ocupación (Montt 2006; Agüero y Uribe 2008).

\section{- Bienes en tránsito del Período Formativo}

Teniendo en cuenta que la evidencia más diagnóstica del Período Formativo registrada en la ruta fue la alfarería, abordaremos las características particulares de la cerámica en relación a su contexto de bienes en tránsito.

Primeramente, el conjunto de materiales cerámicos del Período Formativo se encontró asociado a sitios de descanso (paskanas) y a la Apacheta de Machuca, y no a la vía misma, como sí sucedió en los períodos Medio e Intermedio Tardío. También hay que destacar que la alfarería formativa, aun cuando es escasa $(n=25)$, se distribuye en todo el transecto prospectado, con mayor representación en el ramal a Calar $(n=17)$, justamente en el segmento final de conexión con dicha aldea.

La cerámica corresponde al tipo Los Morros con sus variantes LMS-B1 (SHFCA-O1 y SHFCA-O2) con 12 fragmentos, y a la variante LMS-A (SHTM-O3, SHTM-o 8 y SCMF-O2) con siete fragmentos. Además los tipos LCA (SHFCA-04) con cuatro fragmentos y LRA (SHTMo3, SHMF-14 y SHFCA-04) con dos fragmentos. De acuerdo a la sistematización y análisis de la alfarería formativa realizados en el último tiempo (Uribe y Ayala 2004; Uribe 2006), el tipo Los Morros correspondería a la alfarería más temprana, en particular la variante LMS-A, con fechados por termoluminiscencia entre 960 AC y 341 DC, pero con una mayor incidencia entre 550 y $165 \mathrm{AC}$, lo que se ve apoyado con el amplio registro que existe para la Fase Tilocalar (1400-400 AC) en Tulan (Núñez et al. 2007). Tendría una amplia distribución en el curso inferior del Loa, la Puna Atacameña, el Noroeste Argentino y Altiplano Meridional, sin precisarse hasta ahora su procedencia, aunque Uribe (2006) señala que sería foránea a los oasis de San Pedro.

Por su parte, el tipo Loa Café Alisado (LCA) habría tenido cierta contemporaneidad con el tipo Los Morros, correspondiendo también a evidencias foráneas a los oasis de San Pedro. Se trata de grandes contenedores como ollas y cántaros, vasijas restringidas y con bordes en coma que habrían tenido un uso en contextos domésticos y cotidianos. En tanto, el tipo Loa Rojo Alisado (LRA) corresponde a grandes vasijas restringidas, de base cónica y cuello ancho, de borde convexo y en coma, con asas, que ha sido identificado en contextos habitacionales $y$ cotidianos de los oasis y las quebradas de la cuenca de Atacama desde el Período Formativo al Período Medio e Intermedio Tardío (Uribe 2006).

De acuerdo a estos antecedentes, el tipo LMS con sus variantes LMS-A y LMS-B, junto al tipo LCA, avalarían el uso de la vía desde el Formativo Temprano.Además, la presencia de posibles grandes contenedores para líquidos en contextos de tránsito (LCA, LRA y LMS), podrían indicar una movilidad con recuas de llamas para el Formativo Temprano, situación que tendría que ser evaluada a partir de análisis más intensos de las formas de estos materiales. Asimismo, es destacable la ausencia en la ruta de las cerámicas pulidas más tardías de los oasis de San Pedro: los tipos Toconao (TOC) y Sequitor (SEQ) que han sido identificados principalmente en contextos funerarios de dichos oasis (Uribe 2006), junto a la ausencia de los jarros del tipo LMS-B2. En efecto, las únicas evidencias corresponden a vasijas asociadas a contextos domésticos. Del mismo modo, tampoco se registró alfarería procedente del Altiplano Circumtiticaca (Pukara) y del Noroeste Argentino (Vaquerías), que sí identificó en contextos formativos de los oasis (Uribe 2006).

Es significativa la importante distribución de vasijas Los Morros en la vía, las que incluso han sido identificadas en los sitios de Huayllajara-1 y Ojo del Novillito sobre la misma vía, esta vez en el lado boliviano (Nielsen 2006). Esto es consistente con la amplia dispersión de estos tipos cerámicos desde la cuenca del Loa, Salar de Atacama y vertiente transandina, sugiriendo que 
fue el tipo cerámico (variedades LMS-A y LMS-B) más utilizado en el tránsito interregional del formativo. Una discusión pendiente es aquella sobre el origen de los usuarios de la vía de Tocorpuri en el Formativo, puesto que mientras no se esclarezca el origen de la cerámica Los Morros y Loa Café Alisado, resulta poco prudente aventurar una respuesta.

\section{* Discusión}

Partiendo de la base que en tiempos formativos la región atacameña participó en una amplia red de relaciones socioeconómicas a escala macrorregional, nos propusimos investigar un caso específico de red vial interregional que mostrara comunicaciones directas desde el altiplano boliviano con uno de los centros poblacionales de mayor relevancia de la región como es el caso de los oasis de San Pedro de Atacama. Considerando los bienes foráneos hallados en el oasis atacameño, cabía entonces extender la mirada a aquellos espacios de tránsito donde aún es posible encontrar parte de los vestigios dejados por los antiguos contingentes móviles, aproximándonos a la logística y organización social desplegada en los ejes de movilidad.

En términos cronológicos, hemos sostenido que fue una vía usada en tiempos formativos, dado que muestra una conectividad directa con los asentamientos formativos de Ghatchi y Calar, junto a la presencia discreta pero significativa, de material cerámico diagnóstico del período (tipos LMS-A, LMS-B, LCA y LRA) asociado a sitios de descanso (paskanas) y con una amplia distribución en el transecto vial, los cuales son datos elocuentes para respaldar un temprano tránsito por la ruta de Tocorpuri. Otro dato relevante es que tres de las cinco paskanas identificadas en el trayecto se registraron en el ramal de $5.3 \mathrm{~km}$ que comunicó con la aldea de Calar, lo que permite confirmar la hipótesis inicial de que la conexión última con este nodo formativo debía mostrar mayor intensidad de uso en ese período. En efecto, si bien se identificaron materiales de otros períodos en este tramo, lo que da cuenta de reutilizaciones posteriores, las evidencias más conspicuas nos remiten al Período Formativo. En tal sentido, se constata que el mismo trayecto vial fue utilizado sin variaciones desde el Formativo, continuando en los períodos Medio, Intermedio Tardío, Tardío, Histórico temprano y reciente, indicando que fue el eje principal así como la vía más recta y expedita en términos de costo-beneficio para conectar desde el noreste con los oasis de San Pedro.

Otro aspecto a considerar son las conexiones de la vía hacia la vertiente oriental de la cordillera. Evidentemente al estar limitado nuestro trabajo de campo al lado chileno, las interpretaciones sobre las conexiones con los nodos formativos del altiplano boliviano son sólo aproximativas. La vía continúa hacia el actual territorio boliviano por el sector de Huayllajara (Laguna Colorada), con posibilidades de comunicación hacia el norte con el Altiplano Meridional y Circumtiticaca, y hacia el este con los valles chichas, en la actual frontera argentino-boliviana (Nielsen, com. pers. 2007). Con toda claridad la vía tuvo vínculos con el Altiplano de Lípez, dado que es la primera región que conecta en su entrada a la vertiente oriental. No obstante, hasta donde sabemos no existen referencias sobre centros poblacionales formativos de importancia en esta región ${ }^{11}$, por lo que sería esperable que éste fuese un punto intermedio y no de enlace final de la ruta. Si así fuese, la conectividad hacia el norte debió darse con los nodos formativos del Altiplano Meridional ubicados en las inmediaciones del río Desaguadero y del lago Poopó, como son los sitios de Wankarani, Uspa-Uspa, Chuquiña, San Andrés, entre otros, o aún más al norte con el Altiplano Circumtiticaca y los asentamientos de Tiwanaku, Pukara, Chiripa, Qaluyo u otros (p.e., Ayala 2001; Hastorf et al. 2001; McAndrews 2001).

Cabe recordar que en la vía analizada no registramos bienes procedentes del Altiplano Meridional (p.e., Wankarani) o Circumtiticaca (p.e., Pukara), aun cuando han sido informados fragmentos cerámicos Pukara en contextos habitacionales de San Pedro (Uribe 2006).

\footnotetext{
${ }^{11}$ Es necesario acotar que se han reportado aldeas con componentes formativos tanto en la zona norte de Lípez (Kamash) como en el sureste (aldea de Tiu Khasa) (Arellano 2000; Nielsen 2001a). Sin embargo, ambas tienen ocupaciones multicomponentes tanto del Período de Desarrollos Regionales para el primer asentamiento como del Período
Arcaico para el segundo, lo que dificulta la comprensión sobre la real Desarrollos Regionales para el primer asentamiento como del Período
Arcaico para el segundo, lo que dificulta la comprensión sobre la real dimensión de estos asentamientos para el Formativo.
} 
La infraestructura asociada a la movilidad fue mínima. La vía no tuvo arreglos formales siendo los senderos paralelos, sinuosos y anastomosados lo característico para tiempos formativos. Aun cuando se identificaron pequeñas estructuras de señalización asociadas al eje vial, por ahora no hemos podido establecer una relación directa de estas estructuras con el período de estudio. En cuanto a los sitios de descanso o paskanas, éstos se caracterizan por ser asentamientos menores, de forma semicircular e irregular, con mínima inversión de trabajo, factura expeditiva y escasos fragmentos cerámicos y desechos líticos. El recinto más grande posee tan sólo $8 \mathrm{~m}^{2}$ construidos, mientras que lo más característico son los recintos que van desde $5.5 \mathrm{~m}^{2}$ hasta $1.5 \mathrm{~m}^{2}$, que permitirían alojar a pocas personas, indicando que los contingentes móviles formativos estaban integrados por un bajo número de individuos. Así, se podría suponer que los grupos móviles no estuvieron compuestos por un número importante de personas, situación que parece ajustarse a lo conocido para la etnografía andina (p.e., Casaverde 1977; Göbel 1998; Nielsen 1997, 2001b) donde la organización de la movilidad caravanera recayó en las unidades familiares y más comúnmente en los hombres como los encargados del tráfico interzonal, no existiendo de esta manera una organización centralizada comunitaria en su funcionamiento.

La movilidad con recuas de llamas está avalada por los senderos paralelos del tipo "rastrillado" y anastomosados en los ramales de Ghatchi y Calar, y por los posibles grandes contenedores cerámicos formativos, dado que su traslado debió implicar la utilización de animales de carga. Si consideramos además los datos zooarqueológicos de Tulan y Chiu Chiu que plantean que desde aproximadamente el 2000 AC ya existiría domesticación de camélidos con antecedentes de una temprana orientación zootécnica de la llama como animal de carga (Cartajena 1994; Núñez et al. 2006), en la vía de Tocorpuri podría haber existido un tránsito caravanero desde tiempos tempranos, incluso que se haya iniciado en el Arcaico Tardío. De todos modos, no existen datos concluyentes que permitan asegurar la existencia de una movilidad caravanera en la vía para dicha época, lo que tendrá que evaluarse con futuras excavaciones que se realicen en los sitios de descanso.
Por otra parte, cabe discutir la presencia o no de ritualidad en contexto de tránsito para tiempos formativos, analizándose particularmente el caso de la Apacheta de Machuca. Sobre el origen del ritual de la apacheta existen referencias tan antiguas como las dadas por algunos cronistas coloniales (p.e., Pachacuti Yamqui, Guaman Poma de Ayala) y que posteriormente son retomadas por Hyslop (1984:309), que indican que fue un ritual que surgió y se expandió en los Andes con el Tawantinsuyu. Más recientemente, esto ha sido evaluado con datos procedentes del Camino Inca del Alto Loa (Berenguer et al. 2005) y en el Altiplano de Lípez (Nielsen et al. 2006), quienes a partir de su ausencia en los distintos ejes viales analizados sugieren que podrían haber aparecido en la región en épocas inmediatamente posteriores. Si atendemos a los datos recuperados de la Apacheta de Machuca, observamos la ausencia de materiales incaicos, lo que apoyaría el planteamiento de los autores anteriores. Sin embargo, la importante diversidad de fragmentos cerámicos recolectados, diagnósticos de los períodos Formativo, Medio e Intermedio Tardío, sugiere una gran profundidad cronológica del sitio. A ello también se adiciona nuestro registro de nódulos, lascas, microlascas líticas y el trituramiento de mineral de cobre, así como los antecedentes aportados por Le Paige (1964), quien recolectó de esta apacheta una gran cantidad de puntas de proyectil, que por sus tipologías corresponderían a formas lanceoladas y pedunculadas de filiación arcaica. Todo lo anterior señala una larga data prehispánica que incluso se podría remontar al Período Arcaico, aunque se advierte que esto no necesariamente se vincularía con el origen mismo de la apacheta como estructura, ya que pudo originarse en cualquiera de los períodos involucrados. Con todo y más allá de estas apreciaciones, se puede postular que el sitio como espacio ritualizado - con o sin apacheta-, existió desde por lo menos el Período Formativo, siendo una parada recurrente para los viajeros de distintas épocas, los que mantuvieron en el tiempo una similar significación social del paisaje que normaba para este tipo de espacios transicionales, con alta visibilidad de los puntos de conexión poblacional y del entorno, el pago de ofrendas y la realización de rogativas destinadas a pedir por un buen viaje y favorable intercambio. 
En suma, a partir de un caso de estudio hemos aportado nueva información sobre la infraestructura, organización y prácticas asociadas a la movilidad interzonal del Período Formativo. Hemos sostenido que fue una vía utilizada a lo menos desde esos momentos para conectar el altiplano boliviano con los oasis de San Pedro de Atacama, identificando evidencias directas de sitios de alojamiento y ceremoniales que fueron parte de esa movilidad temprana. También hemos discutido la posibilidad de que una movilidad caravanera haya estado ampliamente activada en tiempos tempranos del Período Formativo. Considerando la baja inversión y tamaño de los campamentos también hemos sugerido que los contingentes móviles eran de pequeña escala, posiblemente tal como ocurre etnográficamente en el Area Andina.

Para finalizar, queremos poner en relieve la necesidad de incrementar los estudios sobre los sistemas viales prehispánicos. Las vías interregionales son espacios privilegiados para aproximarnos a los agentes sociales que dieron vida a los sistemas de intercambio e interacción social que permitieron el ideal andino de complementariedad ecológica, económica y social del cual hablara Murra (1972).
Esperamos que nuevas prospecciones sistemáticas en el área de San Pedro de Atacama, estudios intensivos de los sitios asociados a las vías interregionales, con intervenciones estratigráficas y dataciones absolutas nos acerquen a un mayor reconocimiento de la estructuración de las redes viales de la Subárea Circumpuneña, para lograr una visión integradora en el entendimiento de los procesos y dinámicas sociales interregionales.

Agradecimientos Esta investigación fue posible gracias al financiamiento de los proyectos FONDECYT 1011006 y 1030931. Mis agradecimientos a Carolina Agüero, José Berenguer y Axel Nielsen por los comentarios y observaciones al manuscrito. A Mauricio Uribe, quien realizó el análisis del material cerámico, y a Wilfredo Faúndez, quien me acompañó en las labores de terreno del ramal a Ghatchi y Calar. Del mismo modo, a Indira Montt, José Blanco, Alvaro Reyes y Larry Pérez, por su participación en la campaña de terreno desde Tocorpuri a Catarpe. Por último, mi mayor gratitud a la comunidad de Machuca, en particular a Angel Colque Choque y a su madre, Julia Choque, sabios conocedores de las rutas de los antiguos.

\section{Referencias citadas}

AdÁn, L. y S. Urbina, 2007. Arquitectura formativa en San Pedro de Atacama. Estudios Atacameños, Arqueología y Antropología Surandinas 34: 7-30.

AgüEro, C., 2005. Aproximación al asentamiento humano temprano en los oasis de San Pedro de Atacama. Estudios Atacameños 30: 29-60.

Agüero, C. y M. Uribe, 2008. El Período Formativo en San Pedro de Atacama. Asentamientos, cronología y proceso. Estudios Atacameños, Arqueología y Antropología Surandinas 36. En prensa.

Arellano, J., 200o. Arqueología de Lipes, Altiplano Sur de Bolivia. Museo Jacinto Jijón y Caamaño, PUCE y Taraxacum, Quito.

Ayala, P., 2001. Las sociedades formativas del Altiplano Circumtiticaca y Meridional y su relación con el Norte Grande de Chile. Estudios Atacameños 21: 7-39.

Berenguer, J., 1994. Asentamientos, caravaneros y tráfico de larga distancia en el norte de Chile: El caso de Santa
Bárbara. En Taller De costa a selva. Intercambio y producción en los Andes Centro-Sur, M. E. Albeck (Ed.), pp. 17-5o. Instituto Interdisciplinario Tilcara, Universidad de Buenos Aires, San Salvador de Jujuy.

2004. Tráfico de caravanas, interacción interregional y cambio cultural en la prehistoria tardía del Desierto de Atacama. Ediciones Sirawi, Santiago.

Berenguer, J., I. Cáceres, C. Sanhueza y P. Hernández, 2005. El Qhapaqñan en el Alto Loa, Norte de Chile: Un estudio micro y macromorfológico. Estudios Atacameños 29: 7-39.

BURGER, R., 2006. Interacción interregional entre los Andes Centrales y los Andes Centro-Sur: El caso de la circulación de obsidiana. En Esferas de interacción prehistóricas y fronteras nacionales modernas. Los Andes Sur Centrales, H. Lechtman (Ed.), pp. 423-442. Instituto de Estudios Peruanos, Lima.

Cartajena, I., 1994. Determinación de restos óseos de camélidos en dos yacimientos del Loa Medio (II Región). Estudios Atacameños 11: 25-52. 
Casaverde, R., 1977. El trueque en la economía pastoril. En Pastores de puna: Uywamichiq punarunakuna, J. A. Flores Ochoa (Ed.), pp. 171-192. Instituto de Estudios Peruanos, Lima.

Castro, V., F. Maldonado y M. VÁsquez, 1993. Arquitectura del Pukara de Turi. Actas del XII Congreso Nacional de Arqueología Chilena, pp. 79-106. Temuco.

Castro, V., V. Varela, C. Aldunate y E. Araneda, 2004. Principios orientadores y metodología para el estudio del Qhapaqñan en Atacama: Desde el Portezuelo del Inka hasta Río Grande. Chungara, Revista de Antropología Chilena 36 (2): 463-481.

De Souza, P., C. Sinclaire, R. Molina y F. Gallardo, 2002. Una nota sobre obsidianas de una fuente secundaria en la quebrada de Pelun (localidad de Machuca, San Pedro de Atacama). Boletín de la Sociedad Chilena de Arqueología 33/34: 81-83.

Earle, T., 1991. Paths and roads in evolutionary perspective. En Ancient road networks and settlement hierarchies in the new world, C. D. Trombold (Ed.), pp. 10-16. Cambridge University Press, Cambridge.

Galdames, L. A., 1990. Apacheta: La ofrenda de piedra. Diálogo Andino 9: 11-25.

Göbel, B., 1998. "Salir de viaje”. Producción pastoril e intercambio económico en el Noroeste Argentino. En 50 años de Estudios americanistas en la Universidad de Bonn. Nuevas contribuciones a la arqueología, etnohistoria, etnolingüistica y etnografía de las Américas. 50 Years Americanist Studies at the University of Bonn. New contributions to the archaeology, ethnohistory, ethnolinguistics and ethnography of the Americas, S. Dedenbach-Salazar Sáenz, C. Arellano Hoffmann, E. König, y H. Prümers (Eds.), pp. 867891. Bonner Amerikanistische Studien 30. Verlag Anton Saurwein, Markt Schwaben.

Hastorf, C., M. Bandy, W. T. Whitehead y L. Steadman, 2001. El Período Formativo en Chiripa, Bolivia. Textos Antropológicos 13 (1-2): 17-91.

Hyslop, J., 1984. The Inka road system. Academic Press. Inc., Orlando.

1991. Observations about research on prehistoric roads in South America. En Ancient road networks and settlement hierarchies in the New World, C. D. Trombold (Ed.), pp. 28-33. Cambridge University Press, Cambridge.

IGM, 1990. Geografía II Región de Antofagasta. Colección Geografía de Chile. Instituto Geográfico Militar, Santiago.

LECOQ, P., 1987. Caravanes de lamas, sel et échanges dans une communauté de Potosí, en Bolivie. Bulletin de l'Institut Français d'Etudes Andines 16 (3-4): 1-38.
Le PaIGe, G., 1963-1965. Ghatchi y su zona. Revista Universitaria Año XLVIII, pp. 177-193.

1964. El Precerámico en la cordillera atacameña y los cementerios del Período Agroalfarero de San Pedro de Atacama. Anales de la Universidad del Norte 3.

Llagostera, A., 1988. Informe sobre investigaciones arqueológicas en Calar. Boletín de la Sociedad Chilena de Arqueología 8: 1.

1996. San Pedro de Atacama: Nodo de complementariedad reticular. En La integración surandina cinco siglos después, X. Albó, M. Aratia, J. Hidalgo, L. Núñez, A. Llagostera, M. Remy y B. Revesz (Comps.), pp. 17-42. Universidad Católica del Norte y Centro de Estudios Regionales Andinos Bartolomé de las Casas, Estudios y Debates Regionales Andinos 91, Cusco.

MCAndREWS, T., 2001. Organización y crecimiento de los sistemas de asentamiento tempranos basados en aldeas en el altiplano andino sur-central. Textos Antropológicos 13 (1-2): 135-145.

MontT, I., 2006. Evidencias rupestres de Ghatchi (cuenca del río Vilama, San Pedro de Atacama). Tesis para optar al Grado de Magíster en Antropología Universidad Católica del Norte, Universidad de Tarapacá, San Pedro de Atacama.

MurRa, J. V., 1972. El "control vertical" de un máximo de pisos ecológicos en la economía de las sociedades andinas. En Visita a la Provincia de León de Huánuco (1562), J. Murra (Ed.), pp. 429-476. Universidad Hermilio Valdizán, Huánuco.

Nielsen, A., 1997. El tráfico caravanero visto desde La Jara. Estudios Atacameños 14:339-372.

2001a. Ocupaciones formativas en el Altiplano de LípezPotosí, Bolivia. Textos Antropológicos 13 (1-2): 265-285.

2001b. Ethnoarchaeological perspectives on caravan trade in the South Central Andes. En Ethnoarchaeology of Andean South America. Contributions to archaeological method and theory, L. A. Kuznar (Ed.), pp. 163-201. International Monographs in Prehistory. Etnoarchaeological Series 4, Ann Arbor.

2003. Por las rutas del Zenta: Evidencias directas del tráfico prehispánico entre Humahuaca y las yungas. En La mitad verde del mundo andino: Investigaciones arqueológicas en la vertiente oriental de los Andes y las tierras bajas de Bolivia y Argentina, G. Ortiz y B. Ventura (Eds.), pp. 61-284. Universidad Nacional de Jujuy, San Salvador de Jujuy.

2006. Estudios internodales e interacción interregional en los Andes circumpuneños: Teoría, método y ejemplos de aplicación. En Esferas de interacción prehistóricas y fronteras nacionales modernas. Los Andes Sur Centrales, H. Lechtman (Ed.), pp. 29-62. Instituto de Estudios Peruanos, Lima.

$\mathrm{N}^{\circ} 35 / 2008$ 
Nielsen, A., J. Berenguer y C. Sanhueza, 2006. El Qhapaqñan entre Atacama y Lípez. Intersecciones en Antropología 7 (1-2): 217-234.

NúÑEZ, L., 1976. Geoglifos y tráfico de caravanas en el desierto chileno. Homenaje al Dr. R.P. Gustavo Le Paige, pp. 147-201. Universidad del Norte, Antofagasta.

1984. Tráfico de complementariedad de recursos entre las tierras altas y el Pacífico en el Area Centro-Sur andina. Tesis Doctoral. Departamento de Antropología Cultural, Universidad de Tokio, Tokio.

1985. Petroglifos y tráfico de caravanas en el desierto chileno. En Estudios en arte rupestre, C. Aldunate, J. Berenguer y V. Castro (Eds.), pp. 243-264. Museo Chileno de Arte Precolombino, Santiago.

1992a. Cultura y conflicto en los oasis de San Pedro de Atacama. Editorial Universitaria, Santiago.

1992 b. Ocupación arcaica en la Puna de Atacama: Secuencia, movilidad y cambio. Prehistoria sudamericana. Nuevas perspectivas, B. Meggers (Ed.), pp. 283-308. Taraxacum, Washington D. C.

_ 1994. Emergencia de complejidad y arquitectura jerarquizada en la Puna de Atacama: Evidencias del sitio Tulan-54. En Taller De costa a selva, Intercambio y producción en los Andes Centro-Sur, M. E. Albeck(Ed.), pp.85-108. Instituto Interdisciplinario de Tilcara, Universidad de Buenos Aires, San Salvador de Jujuy.

NúÑEz, L.y T. DılleHAY, 1995 [1979]. Movilidad giratoria, armonía social y desarrollo en los Andes Meridionales: Patrones de tráfico e interacción económica (Ensayo). Universidad del Norte, Antofagasta.

NúÑez, L., I. Cartajena, J. P. Loo, S. Ramos, T. Cruz y H. Ramírez, 1997. Registro e investigación del arte rupestre en la cuenca de Atacama (Informe preliminar). Estudios Atacameños 14: 307-325.

Núñez, L., I. Cartajena, C. Carrasco. P. De Souza y M. Grosjean, 2006. Emergencia de comunidades pastoralistas formativas en el sureste de la Puna de Atacama. Estudios Atacameños, Arqueología y Antropología Surandinas, 32: 93-117.

NúÑez, L., P. De Souza, I. Cartajena y C. CarRasco, 2007. Quebrada Tulan: Evidencias de interacción circumpuneña durante el Formativo Temprano en el sureste de la cuenca de Atacama. En Producción y circulación de bienes en el sur andino, A. Nielsen, C. Rivolta, V. Seldes, M. Vásquez y P. Mercolli (Eds.), pp. 287 304 Editorial Brujas, Córdoba.

Orellana, M., 1988-89. Los tipos alfareros tempranos de Calar y su contexto aldeano. Paleoetnológica 5: 73-86.
1990. Calar: Una aldea temprana del norte de Chile. Creces $3(11): 23-28$.

Philippi, R., 1860. Viage al Desierto de Atacama hecho de orden del Gobierno de Chile en el verano 1853-54. Librería de Eduardo Antón, Santiago.

Pimentel, G., 2004. Vías de circulación del Período Intermedio Tardío (ca. 900-1450 DC) en las tierras altas de la localidad de Caspana (II Región). Una aproximación a la estructuración local, regional e interregional. Tesis para optar al Título Profesional de Arqueólogo. Departamento de Antropología, Universidad de Chile, Santiago.

Pimentel, G., I. Montt, J. Blanco y A. Reyes, 2007. Infraestructura y prácticas de movilidad en una ruta que conectó el altiplano boliviano con San Pedro de Atacama (II región, Chile). En Producción y circulación de bienes en el sur andino, A. Nielsen, C. Rivolta, V. Seldes, M. Vásquez y P. Mercolli (Eds.), pp. 351-282. Editorial Brujas, Córdoba.

Trombold, C. D., 1991. An introduction to the study of ancient New World road networks. En Ancient road networks and settlement hierarchies in the New World, C. D. Trombold (Ed.), pp. 1-9. Cambridge University Press, Cambridge.

URIBE, M., 2006. Sobre cerámica, su origen y complejidad social en los Andes del Desierto de Atacama, norte de Chile. En Esferas de interacción prehistóricas y fronteras nacionales modernas. Los Andes Sur Centrales, H. Lechtman (Ed.), pp. 449-493. Instituto de Estudios Peruanos, Lima.

URIBe, M. y P. Ayala, 2004. La alfarería de Quillagua en el contexto formativo del Norte Grande de Chile (1000 AC-500 DC). Chungara, Revista de Antropología Chilena no especial, vol. 2, pp. 585-598.

VAn Kessel, J., 1992. Tecnología aymara: Un enfoque cultural. En Tecnología andina: Una introducción. J, Earls, E. Grillo, H. Araujo y J. Van Kessel (Eds.), pp. 143-226. Hisbol, La Paz.

Villagrán, C., V. Castro, G. Sánchez, M. Romo, C. Latorre y L. Hinojosa, 1998. La tradición surandina del desierto: Etnobotánica del área del Salar de Atacama (provincia de El Loa, región de Antofagasta, Chile). Estudios Atacameños 16:107-170.

VITRY, C., 2002. Apachetas y mojones, marcadores espaciales del paisaje prehispánico. Revista Escuela de Historia 1 (1): 179-191.

YACOBACCIO, H., 1979. Arte rupestre y tráfico de caravanas en la Puna de Jujuy: Modelo e hipótesis. Antiquitas 2:392-407. 